
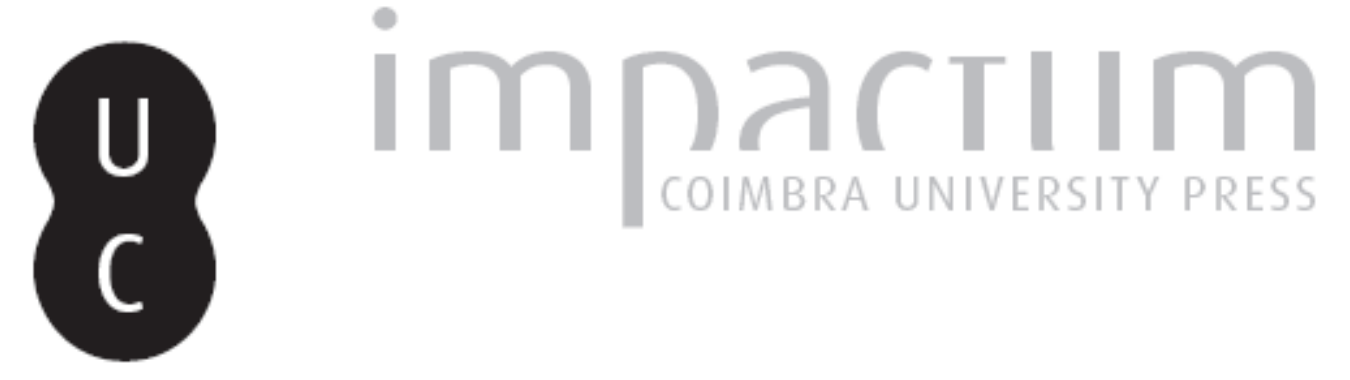

\title{
O tempo de resposta do ataque inicial a incêndios florestais nos espaços mais sensíveis de Portugal: o exemplo prático da serra da Lousã
}

Autor(es): $\quad$ Félix, Fernando; Lourenço, Luciano

Publicado por: Associação Portuguesa de Riscos, Prevenção e Segurança; Imprensa

URL

persistente:

da Universidade de Coimbra

DOI: $\quad$ DOI:https://doi.org/10.14195/1647-7723_24_14

Accessed : $\quad$ 26-Apr-2023 05:39:59

A navegação consulta e descarregamento dos títulos inseridos nas Bibliotecas Digitais UC Digitalis, UC Pombalina e UC Impactum, pressupõem a aceitação plena e sem reservas dos Termos e Condições de Uso destas Bibliotecas Digitais, disponíveis em https://digitalis.uc.pt/pt-pt/termos.

Conforme exposto nos referidos Termos e Condições de Uso, o descarregamento de títulos de acesso restrito requer uma licença válida de autorização devendo o utilizador aceder ao(s) documento(s) a partir de um endereço de IP da instituição detentora da supramencionada licença.

Ao utilizador é apenas permitido o descarregamento para uso pessoal, pelo que o emprego do(s) título(s) descarregado(s) para outro fim, designadamente comercial, carece de autorização do respetivo autor ou editor da obra.

Na medida em que todas as obras da UC Digitalis se encontram protegidas pelo Código do Direito de Autor e Direitos Conexos e demais legislação aplicável, toda a cópia, parcial ou total, deste documento, nos casos em que é legalmente admitida, deverá conter ou fazer-se acompanhar por este aviso. 


\section{MULTIDISCIPLINARIDADE NA ANÁLISE DAS MANIFESTAÇÕES DE RISCO}

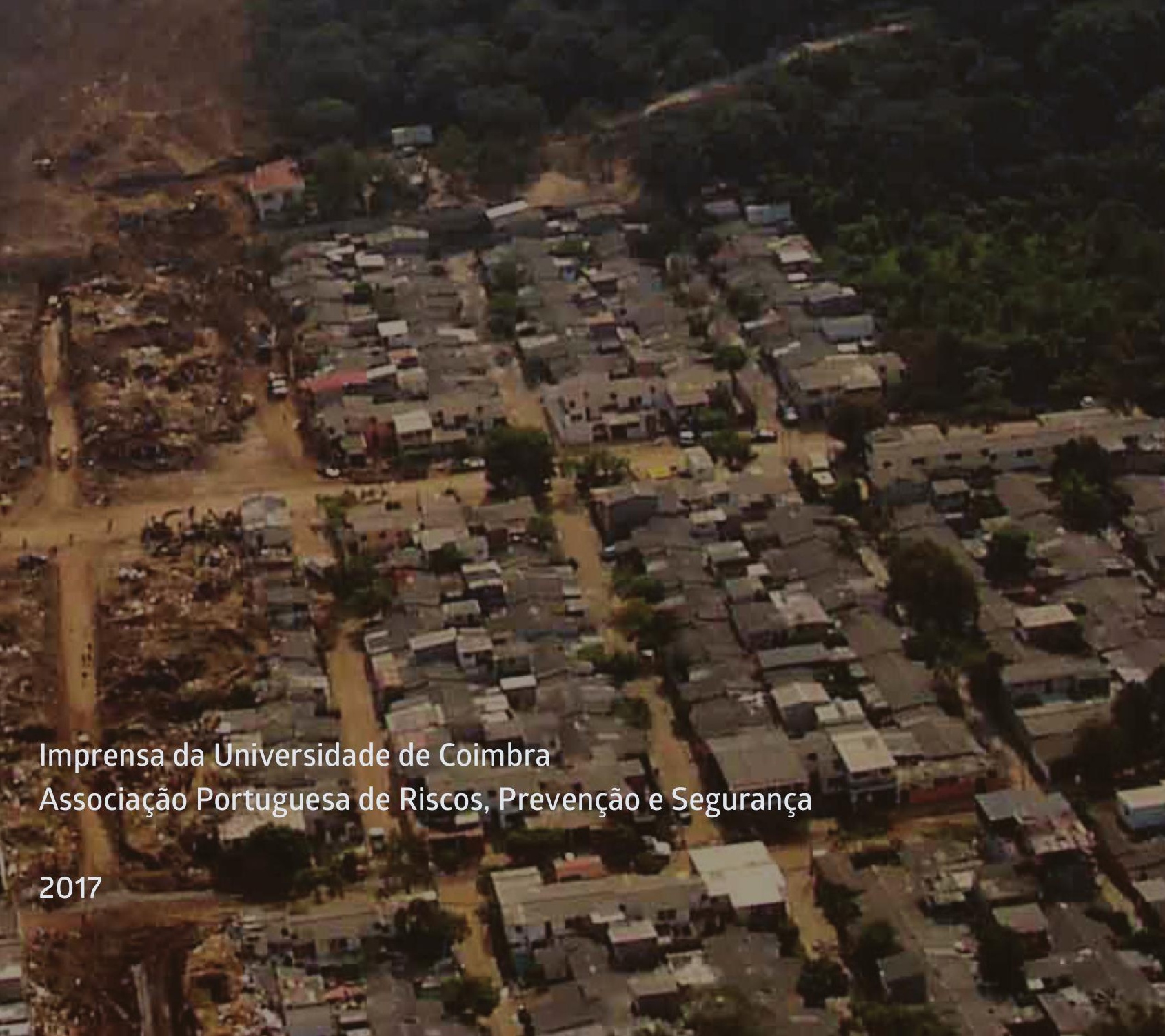




\title{
O TEMPO DE RESPOSTA DO ATAQUE INICIAL A INCÊNDIOS FLORESTAIS NOS ESPAÇOS MAIS SENSÍVEIS DE PORTUGAL. O EXEMPLO PRÁTICO DA SERRA DA LOUSÃ
}

\author{
THE INITIAL ATTACK RESPONSE TIME TO FOREST FIRE IN THE MOST SENSITIVE AREAS OF PORTUGAL. \\ THE PRACTICAL EXAMPLE OF LOUSÃ MOUNTAIN
}

Fernando Félix

NICIF- Núcleo de Investigação Científica de Incêndios Florestais e RISCOS, Universidade de Coimbra ffelix@fl.uc.pt

Luciano Lourenço

Departamento de Geografia e Turismo, CEGOT e RISCOS, Universidade de Coimbra luciano@uc.pt

\section{RESUMO}

A ocorrência de incêndios florestais necessita da conjugação de condições atmosféricas favoráveis, vegetação combustível e uma fonte de ignição. Reunidas estas três condições, os incêndios florestais começam, normalmente, por ser pequenas fogueiras. Depois, a reposta do ataque inicial determina, quase sempre, as características que os incêndios acabam por assumir, pelo que o tempo necessário para essa resposta deverá estar em consonância com as características intrínsecas a cada um dos espaços florestais, para assim se mitigarem as consequências e reduzirem as dimensões das áreas ardidas.

Palavras-chave: Ataque inicial, tempo de resposta, sensibilidade, incêndios florestais, serra da Lousã.

\section{ABSTRACT}

The occurrence of forest fires requires the combination of favorable weather conditions, vegetation as the fuel and a source of ignition. When these three conditions are witnessed forest fires start, usually, as small fires. After the ignition, the initial attack response time often determine the characteristics which the fires eventually end up taking, therefore response time for the initial attack should be in accordance with the intrinsic characteristics of each forest areas, in order to mitigate its consequences and reduce the size of the burnt areas.

Keywords: Initial attack, response time, sensitivity, forest fires, Lousã Mountain.

\section{RESUMÉ}

El tiempo de respuesta del ataque inicial a incendios forestales en espacios más sensibles de Portugal. El ejemplo práctico de la Sierra da Lousã - La ocurrencia de incendios forestales necesita en simultáneo, de condiciones meteorológicas favorables, vegetación combustible y una fuente de ignición. Una vez reunidas estas tres condiciones, los incendios forestales empiezan por pequeños fuegos. Va a ser la respuesta del ataque inicial que, casi siempre, determina las características que los incendios acaban teniendo, por lo que el tiempo necesario para esa respuesta debe estar en consonancia con las características intrínsecas de cada una de las áreas forestales, para con ello mitigar las consecuencias y reducir el tamaño de las zonas quemadas.

Mots-clé: Ataque inicial, tiempo de respuesta, sensibilidad, incendios forestales, sierra de Lousã.

\section{RESUMEN}

Temps de réponse pour l'attaque initiale contre les incendies de forêt dans les zones les plus sensibles du Portugal. Exemple de la montagne Lousã - Le déclenchement de feux de forêt nécessite la combinaison de conditions météorologiques favorables, de la végétation comme combustible et d'une source d'inflammation. Lorsque ces trois conditions sont réunies, les feux commencent généralement par un petits foyer. Après l'allumage, le temps initial de départ de feu concorde souvent avec les caractéristiques de l'évolution des feux, donc le temps de réponse pour l'attaque initiale devrait être en corrélation avec les caractéristiques intrinsèques de chaque zone forestière, afin d'atténuer les conséquences et de réduire la taille des zones brûlées.

Palabras clave: Attaque initiale, temps de réponse, sensibilité, incendies de forêt, montagne de Lousã.

* O texto deste artigo corresponde a uma comunicação apresentada no I Seminário da Rede Incêndios-Solo e I Simpósio Ibero-Afro-Americano de Riscos, tendo sido submetido em 28-12-2015, sujeito a revisão por pares a 09-01-2016 e aceite para publicação em 05-04-2016.

Este artigo é parte integrante da Revista Territorium, $n .{ }^{\circ} 24,2017,{ }^{\circ}$ RIscos, ISSN: 0872-8941. 
Introdução

Infelizmente, em Portugal todos os anos falamos das florestas, mas mais pelas más do que pelas boas razões, uma vez que a atenção recai principalmente na floresta que arde, pondo em riscos pessoas e bens. Tem sido assim nas últimas décadas (J. S. Pereira, 2013), mas não foi sempre assim! De facto, parafraseando o Eng. ${ }^{\circ}$ Moreira da Silva, "os incêndios florestais são uma calamidade, mas não são uma fatalidade", como a sua frequência parece fazer parecer.

Num passado não muito distante, até aos inícios da década de 70 , os incêndios não eram considerados um problema para a floresta em Portugal. "O agricultor, pastor, coexistia em harmonia com o fogo, com sabedoria realizava queimadas dos resíduos de exploração agrícola, queimava para renovar pastagens, e quando alguma se descontrolava, havia uma entreajuda dos habitantes da aldeia e arredores por forma a que o fogo não alastrasse" (C. Colaço, 2005). As florestas sob administração do Estado tinham gente, que nela trabalhava e vivia, pelo que cada Cantão estava sob a responsabilidade de um Guarda-Florestal que fiscalizava as diversas ações sobre o território. 0 Guarda-florestal tinha a seu cargo tinha ao seu encargo capatazes e jornaleiros que trabalhavam e cuidavam da terra, além de colaborarem na deteção de fogos que, quando avistados, fazia com que esses trabalhadores se transformassem numa força específica de combate ao incêndio que, por já se encontrar nesse cantão, procedia ao combate. Caso não conseguisse extinguir o incêndio o Guarda-Florestal tinha autonomia para contratar mais jornaleiros para ajudarem no combate.

Contudo, as mudanças socioeconómicas iniciadas nos anos 50 e 60 do século passado (Lourenço, 1991a; Vélez, 1993; Moreno et al., 1998; Rego, 2001), traduziram-se em forte êxodo rural, com o consequente abandono de viver no e do campo, bem como dos seus modos de vida, o que implicou uma drástica redução do pastoreio e roça de matos nos espaços agro-silvo-pastoris, levando a que muitos dos campos agrícolas, outrora cultivados, e penosamente cuidados, fossem abandonados e consequentemente invadidos pela floresta circundante (Lourenço, 1991a; Rego, 1992; García-Ruiz et al., 1996). Entretanto, a arborização de vastos espaços comunitários serranos, os baldios, proporcionou uma extensa e contínua área florestal, geralmente monoespecífica, nem sempre devidamente ordenada, que fez aumentar a disponibilidade de combustível, o que contribuiu para o aumento do risco de incêndio florestal (Bento-Gonçalves et al., 2010). Muitas destas áreas rurais tornaram-se paisagens propensas à ocorrência de incêndios de grande intensidade, devido aos elevados níveis de biomassa, acumulados ao longo dos anos e prontos para alimentar incêndios catastróficos (F. Ferreira-Leite et al., 2014).
Estas marcadas alterações do território, fizeram com que a década de 70 do século passado tivesse marcado "o início de uma fase de incremento tanto do número de incêndios como da dimensão das áreas ardidas" (Flora FerreiraLeite, 2014). Os fogos tornaram-se mais recorrentes (F. Ferreira-Leite et al., 2014) e aumentaram em intensidade e extensão, tomando dimensões catastróficas (R. Noss et al., 2006). Exemplo disso foi o facto de "na década de 80 , do século anterior, se ter ultrapassado o limiar dos 10. 000ha de área ardida por um só incêndio" (Flora Ferreira-Leite, 2011). O primeiro destes ocorreu no ano de 1986, nos concelhos de Vila de Rei e Ferreira do Zêzere e, o segundo, no ano seguinte, 1987, tendo afetado os concelhos de Arganil, Oliveira do Hospital e Pampilhosa da Serra (Lourenço, 1988). A partir destas datas podemos dizer que se deu início a uma nova realidade no que respeita aos grandes incêndios florestais.

Contudo, para além das mudanças sentidas no uso do solo, resultantes da desarticulação do mundo rural, uma outra profunda alteração, de nível operacional, veio contribuir para o atual panorama, a qual se prende com o facto do combate aos incêndios florestais ter passado para os bombeiros. Com efeito, até então era da responsabilidade dos Serviços Florestais do Ministério da Agricultura que, com uma experiência secular, tinham uma primeira intervenção eficaz, mas com a publicação do Decreto Regulamentar n. ${ }^{\circ} 55 / 81$, de 18 de Dezembro, a situação modificou-se, tendo-se dividido e clarificado as competências das duas instituições. Tendo passado para os Corpos de Bombeiros a responsabilidade do combate e rescaldo dos incêndios florestais (L. Lourenço, 2006), uma força que, na altura, não estava estruturalmente organizada, nem dotada de meios e técnicas adequadas ao combate a incêndios florestais, especialmente em áreas de montanha, pelo que esta transferência de competências não foi bem aceite pelos florestais.

No presente estudo é importante referir que na primeira situação os meios e os equipamentos encontravam-se nas áreas florestais, podendo iniciar de imediato o combate, reduzindo assim o tempo de resposta, enquanto que, depois, passaram a estar sediados nos quarteis de bombeiros. Este facto, contribui para o aumento de tempo, no que respeita à resposta por parte dos bombeiros, um a vez que este se encontram afastados dos locais onde são necessários. Assim, diminui a rapidez do ataque inicial dos meios de combate.

Em resultado de todas estas transformações iniciadas em meados do século passado, os valores dos últimos anos relativos às áreas ardidas e ao número de ignições, são avassaladores (Conceição Colaço, 2006). Comparando com os restantes países da bacia mediterrânica, Espanha, França, Itália e Grécia, Portugal foi o único país que mantém uma tendência diferente dos restantes países, com a média da área ardida a aumentar desde 1980 e 
com a média anual do número de incêndios entre 1980 e 2003 ultrapassa as 16500 enquanto nos outros países os valores encontram-se todos abaixo desta fasquia (European Commission, 2004 in Conceição Colaço, 2006).

“A extensão e violência dos incêndios de 2003 e 2005 expuseram as vulnerabilidades do território português" (J. S. Pereira, 2013) e as "deficiências do sistema de prevenção e socorro” (A. Amaro, 2009).

Embora Portugal, na sequência destes dois anos catastróficos, tenha produzido grandes quantidades de legislação florestal, nos seus vários domínios e tenha realizado várias e profundas alterações à lei orgânica de proteção civil e ao modo que este se organiza o socorro e nele interagem os seus diversos agentes, designado por SIOPS (Sistema Integrado de Operações de Socorro), nem sempre a sua aplicação tem resultado. De facto, a delineação de diversos planos obedece a modelos demasiado rígidos, por serem elaborados e impostos por regulamentação de âmbito nacional, não prevendo, por isso, a adaptação às realidades locais, o que dificulta e fragiliza a sua aplicação (F. Tedim et al, 2013) e que se traduz numa operacionalização menos eficaz, ao não analisarem as vulnerabilidades de cada território, tendo em conta as respetivas especificidades, o que faz com que, operacionalmente, nem sempre as estratégias decorram conforme foram delineadas e planeadas no papel.

Portugal continuou a arder (Vieira, 2006)! Para travar esta calamidade, as entidades políticas adotaram muitas estratégias mas sem terem alcançado os resultados pretendidos, pois a resposta das autoridades competentes tem sido sempre a mesma, o reforço do investimento na aquisição de mais meios e em ações de combate (M. Serrano e V. Martins, 2002 in J. Aranha, 2004), o que fez com que Portugal tenha sido nas últimas décadas o país da Europa com maior proporção de área florestal ardida em cada ano. É assim desde os anos 70 (J. S. Pereira, 2013).

Assim quando as condições atmosféricas são mais severas, quer dentro quer fora do designado período critico, as ignições proliferam por todo Portugal e os fogachos rapidamente evoluem para incêndios florestais incontroláveis, em que o Dispositivo Especial de Combate aos Incêndios Florestais (DECIF) se torna incapaz de travar e controlar a sua evolução. Como consequência, destroem-se hectares de floresta, em que bens e pessoas são ameaçados, obrigando ao reforço dos meios iniciais de combate, que, muitas vezes, são divididos entre o combate ao incêndio e a proteção e defesa das populações, podendo mesmo proceder à sua evacuação, o que leva a uma grande distribuição espacial dos meios de combate pelo território. Acresce que, geralmente, estas áreas apresentam acessibilidades muito reduzidas, com caminhos florestais estreitos e muito sinuosos, frequentemente em mau estado de conservação e sem permitirem o cruzamento de veículos, o que pode fazer aumentar a distância a percorrer entre os quartéis e os locais de ignição, bem como nos deslocamentos aos pontos de água mais próximos, para reabastecer e, depois, voltar para a frente de combate ao incêndio, enquanto as chamas progridem por vales e vertentes, aspeto que agrava o risco de incêndios destas áreas.

\section{Área de estudo}

Apesar dos distritos do litoral terem um maior número de ocorrências, fruto das elevadas densidades populacionais e de uma mistura complexa de vários tipos de uso do solo, é nos distritos da Região Centro e no interior de Portugal onde os grandes incêndios florestais se fazem mais sentir, traduzindo-se em grandes áreas ardidas (M. Pereira et al., 2005). Pelo que a expectativa de área queimada, associada a estas ignições em áreas de montanha é dezenas ou centenas de vezes maior do que a das áreas costeiras (J. Pereira et al., 1998).

Face à problemática que os incêndios florestais assumem na região Centro e com real destaque para a área ardida escolhemos a serra da Lousã como área de estudo, que se expande pelos municípios de Penela, Miranda do Corvo, Lousã e Góis, do distrito de Coimbra e Figueiró dos Vinhos, Castanheira de Pera e Pedrogão Grande, do distrito de Leiria.

No entanto, face aos diversos dados utilizados, as áreas do concelho analisadas variam. Assim para o estudo das áreas ardidas utilizou-se os dados fornecidos pelo ICNF - Instituto de Conservação da Natureza e das Florestas, onde temos os valores totais da área municipal, assim como para as corporações de bombeiros e seus meios de combate foram levantados os totais municipais. A população residente (Censos de 2011) dizem respeito, também, aos totais municipais. No entanto, para os tempos de resposta foram cadastradas as estradas principais dos quarteis de bombeiros à serra da Lousã, definindo deste modo a quadricula da área de de estudo (fig. 2), pelo que aqui os valores não são os municipais.

Dentro dos municípios que pertencem à serra da Lousã a área de estudo de cada concelho é diferente (TABELA I). 0 único que foi abrangido na sua plenitude foi o concelho de Castanheira de Pera (100\%), seguido pelos concelhos da Lousã $(80,5 \%)$ e Miranda do Corvo (70\%). Os menos abrangidos são os de Figueiró dos Vinhos (39\%), Pedrogão Grande (38\%) e Penela (37\%).

\section{Objetivos}

Uma vez que o Dispositivo Especial de Combate aos Incêndios Florestais (DECIF), independente do seu maior ou menor orçamento, não tem conseguido controlar todos os focos iniciais de incêndios, tendo deixado evoluir alguns deles para situações incontroláveis, este estudo 
TABELA I - Caraterísticas dos municípios da área de estudo.

TABLE I - Municipalities characteristics in the of study area.

\begin{tabular}{|c|c|c|c|c|c|c|}
\hline \multirow{2}{*}{ Concelho } & \multirow{2}{*}{$\begin{array}{l}\text { Distrito } \\
\text { Hectares }\end{array}$} & \multicolumn{2}{|c|}{ Área total } & \multirow[t]{2}{*}{$\begin{array}{c}\text { Área de } \\
\text { Estudo }\end{array}$} & \multirow{2}{*}{$\begin{array}{c}\text { Percentagem } \\
\%\end{array}$} & \multirow{2}{*}{$\begin{array}{c}\text { Estrada } \\
\mathrm{Km}\end{array}$} \\
\hline & & $\mathrm{Km}^{2}$ & $\mathrm{~km}^{2}$ & & & \\
\hline Ansião & Leiria & 17609,4 & 176,09 & 0,13 & 0,07 & 0 \\
\hline Castanheira de Pera & Leiria & 6677,5 & 66,78 & 66,78 & 100,00 & 76,89 \\
\hline Coimbra & Coimbra & 31939,9 & 319,40 & 0,33 & 0,10 & 0 \\
\hline Figueiró dos Vinhos & Coimbra & 17344,0 & 173,44 & 67,69 & 39,03 & 44,61 \\
\hline Góis & Coimbra & 26330,2 & 263,30 & 158,30 & 60,12 & 161,35 \\
\hline Lousã & Coimbra & 13840,0 & 138,40 & 111,38 & 80,48 & 177,46 \\
\hline Miranda do Corvo & Coimbra & 12637,8 & 126,38 & 88,96 & 70,39 & 151,20 \\
\hline Oleiros & Castelo Branco & 47109,3 & 471,09 & 2,94 & 0,62 & 0 \\
\hline Pampilhosa da Serra & Coimbra & 39646,2 & 396,46 & 16,40 & 4,14 & 0 \\
\hline Pedrogão Grande & Leiria & 12874,8 & 128,75 & 49,32 & 38,31 & 46,97 \\
\hline Penela & Coimbra & 13480,0 & 134,80 & 50,53 & 37,48 & 73,62 \\
\hline Sertã & Castelo Branco & 44673,2 & 446,73 & 0,23 & 0,05 & 0 \\
\hline Total & 3 & 284162,3 & 2841,6 & 612,99 & 57,47 & 732,09 \\
\hline
\end{tabular}

Fonte: Elaboração própria, com base em dados CAOP 2012 - DGT. Source: Own elaborated, based on CAOP 2012 data - DGT

pretende demonstrar como algumas condicionantes poderão ser potenciadas por forma a aumentar a eficácia dos meios de combate aos incêndios florestais e, assim, diminuir as áreas ardidas.

Deste modo, os objetivos específicos consistem essencialmente em demonstrar a importância do factor declive na gestão do risco de incêndio florestal, por este não só fazer aumentar a sensibilidade/fragilidade dos espaços florestais, mas também por condicionar fortemente o combate aos incêndios, sobretudo quando se trata de espaços mais sensíveis e que, por conseguinte, necessitam de uma estratégia de combate especial, assegurando um ataque inicial ainda mais atempado, em consonância com o comportamento que o fogo assume nas áreas com fortes declives. Assim, além deste, ainda foram definidos os seguintes objetivos específicos:

- Averiguar a relação existente entre os recursos disponíveis (quadro de elementos no ativo e número de meios terrestres disponíveis para combate a incêndios florestais) não só com a população residente, mas também como com a área florestal a proteger;

- Analisar a importância do relevo tanto para o índice de sinuosidade rodoviária, como para os tempos de deslocação dos meios de combate, agrupados por classes: 1-5 min; 6-10 min; 11-15 min; 16-20 min e $>20$ min;

- Analisar os Grandes Incêndios Florestais, pois, apesar do seu reduzido número, são responsáveis pelas principais áreas ardidas, designadamente em termos do tempo de chegada da Primeira Intervenção;
- Demonstrar a importância do destacamento de meios terrestres de ataque inicial para locais estratégicos de pré-posicionamento, de modo a aumentar a eficácia da primeira intervenção nas áreas mais sensíveis;

\section{Metodologia}

Para proceder à análise dos tempos de deslocação dos meios de primeira intervenção com o objetivo de verificar as suas relações com as áreas ardidas, recolhemos os dados oficiais, estatísticos e cartográficos, disponibilizados pelo ICNF na sua página web sobre incêndios florestais, relativas ao período de 2001 a 2013, pois são aquelas que têm campos que descriminam a data da ocorrência, hora do alarme, hora da $1 .^{a}$ intervenção e hora de extinção.

Depois,foram selecionados apenas os concelhos da serra da Lousã: Penela, Mirando do Corvo, Lousã e Góis, do distrito de Coimbra; Castanheira de Pera, Figueiró dos Vinhos e Pedrogão Grande, do distrito de Leiria.

Porque interessa tratar só os incêndios florestais, no campo relativo aos "Tipos", procedeu-se à eliminação dos "Agrícolas", "Falsos alarmes" e "Reacendimentos", tendo-se considerado apenas o código "Florestal”.

Depois, como pretendíamos realizar diversas análises, demos destaque a alguns dos campos para que existe informação, nomeadamente aos seguintes: "DataAlerta", referente à data da ocorrência; "HoraAlerta”, relativo à hora de deteção da ignição; "Hora1Interv", correspondente à hora de início da 
primeira intervenção; “DataExtinção”, referente à data da extinção; "HoraExtinção", relativo à hora de extinção e AA_EspaçoFlorestal (Pov+mato)", correspondente ao total da área ardida, independentemente de ser em floresta ou em mato.

Estabilizados os dados e enquadrados os anos, procedemos ao cálculo do tempo que demorou o começo do ataque inicial. Para esse efeito, subtraímos às "Hora1Interv" as respetivas "HoraAlerta", cujos resultados foram normalizados em cinco classes. Apesar de os cálculos terem sido realizados às milésimas der segundos (00:00’01), por uma questão de simplificação as legendas dos quadros e das figuras dizem respeito apenas aos minutos (1-5, 6-10, 11-15, 16-20 e >20 minutos).

Terminada esta tarefa de normalização dos dados, foram removidos os anos de 2002, 2003 e 2004, visto que não tinham dados robustos, pelo que no final acabaram por ser considerados apenas 10 anos com incêndios.

As estradas foram cadastradas com recurso a ortofotomapas de 2005, e sempre que necessário com a conversão em ficheiros de $\mathrm{KMZ}$ para visualização no Google Earth. Os dados do uso do solo foram obtidos através do Corine Land Cover 2006 e a informação da altimetria da DGT - Direção Geral do Território e do Atlas do Ambiente. Os dados vetoriais referentes ao Municípios foram retirados da CAOP - Carta Oficial Portuguesa 2012.

Embora os grandes incêndios florestais ( $\geq 100$ ha) sejam estatisticamente irrelevantes em termos das ocorrências registadas em Portugal, mas porque são responsáveis pela maioria da área ardida anualmente, merecem a nossa atenção.

\section{A serra da Lousã}

"Serra, montanha, monte muito alto e extenso, terreno acidentado entrecortado de vales $e$ escarpas, elevação, sinónimo do termo e da nossa gente e região, que existe e se assume em torno da pedra que a forma e lhe dá o nome... lousa... ou xisto, pedra negra e agreste, tão idêntica à alma dos povos de antanho que a habitam e a sulcaram, para além da inacessibilidade dos seus trilhos ou mais tarde, já em meados bem entrados do século XX, da sua estrada sinuosa." (Ana Souto, 2006).

A serra da Lousã é uma espécie de guarda avançada que marca o limite ocidental da Cordilheira Central, o mais importante bloco montanhoso do nosso país e a espinha dorsal da Península Ibérica (P. Dias e F. Rebelo, 1985; P. Carvalho, 2008).

Do ponto de vista administrativo, a serra da Lousã está enquadrada, a nível da Nomenclatura das Unidades Territoriais, na NUT III do Pinhal Interior Norte e faz a transição administrativa entre os distritos de Coimbra e de Leiria. Assim, o norte da serra pertence ao distrito de Coimbra, abrangendo os concelhos de Penela, Miranda do Corvo, Lousã e Góis. Por sua vez, o sul, integra o distrito de Leiria, com os concelhos de Figueiró dos Vinhos, Castanheira de Pera e Pedrogão Grande.

Com uma orientação nordeste/sudoeste, tem aproximadamente 30 quilómetros de comprimento e a altitude máxima de 1205 metros, no ponto denominado "Altar de Trevim". A rede hidrográfica drena toda a serra, localizando-se maioritariamente a sudeste e, em particular, no concelho da Pampilhosa da Serra (fig. 1).

A serra da Lousã é fortemente sulcada por uma rede ramificada de vales que, ao erguer-se abruptamente dos 200 até perto dos 900-1000 metros de altitude (fig. 1 - A), coloca uma forte barreira à passagem de uma vertente para a outra da serra, sobretudo devido aos declives abruptos do seu rebordo Noroeste (Alegria, 1976).

Assim, na base da serra, a Noroeste, observamos áreas aplanadas que esbarram com fortes declives a Sueste até se atingirem as linhas de cumeada (800-1200m). À medida que, depois, nos deslocamos para Sul, os declives tendem a ficar mais suaves (fig. 1-B), (F. Félix, 2014).

Este relevo vigoroso, fez com que a serra da Lousã tivesse uma herança pesada, devido aos seus constrangimentos estruturais, onde está patenteado o isolamento, com incidência secular, transversal a toda a serra (P. Carvalho, 2008).

A. Matos (1980) refere que os elementos de ordem natural foram desenhando o traçado das estradas de Portugal, pelo menos até meados de oitocentos, onde a "rede de estradas se concentrava no litoral, acompanhando e penetrando, sempre que possível, a rede fluvial navegável, mas diluindo-se nas zonas montanhosas do interior". Estas regiões, já de si débeis, viam-se isoladas pelos custos onerosos que a implementação de uma estrada em montanha acarreta. Em 1977, a JAE (Junta Autónoma de Estradas) informou que “(...) a rede rodoviária nacional encontra-se numa situação de completo desajustamento (...). Traçados sinuosos $e$ estreitos, com pavimentos em degradação progressiva a atingirem o colapso" (JAE/MEPAT, 1997). Assim, o acesso ao interior da serra da Lousã era realizado "por caminhos de muito difícil traçado e quase sempre em mau estado de conservação" (P. Carvalho, 1998 e 2008).

Deste modo, a serra da Lousã ocupou uma posição geográfica semi-periférica em relação aos principais eixos rodoviários de circulação regional e nacional, e a modernização do seu sistema rodoviário "processou-se de uma forma lenta" (M. Alegria, 1990 in P. Carvalho 2008).

"Depois, na década de 90, foi lançado o IC8 que cruza a extremidade sudoeste da serra e faz a ligação de Castelo Branco ao IC3 (Setúbal-Tomar-Coimbra) e ao IC2 
(em Pombal) assumindo-se na atualidade como a mais importante via regional. Contudo, estando situado nas bordaduras da serra, o espaço de montanha continua caracterizado por vias de cariz local, que asseguram movimentos pendulares e a ligação aos centros urbanos mais próximos e às sedes concelhias, bem como a ligação à Rede Nacional Fundamental (IP, IC, ER), ainda que com fraca qualidade" (F. Félix, 2014).

Com a inexistência de trabalhadores florestais nos diferentes Cantões e Perímetros Florestais, onde, até 1981, combatiam os incêndios, e com o posterior estacionamento dos meios de combate nos quartéis dos bombeiros, o ataque inicial aos incêndios florestais ficou mais demorado. Com efeito, a localização dos quartéis a baixas cotas, a par de um sistema rodoviário sem vias de hierarquia superior, coloca entraves à deslocação dos meios em terrenos mais acidentados. De facto, devido à sua sinuosidade, as estradas não permitem velocidades altas e aumentam a distância que seria necessário percorrer se elas fossem retas e, por conseguinte, ampliam o tempo que seria necessário para ir do ponto $\mathrm{A}$ ao ponto $B$, numa estrada retilínea.

\section{Os corpos de bombeiros da serra da Lousã}

Na serra da Lousã existem 8 Corpos de Bombeiros, com duas secções destacadas, contabilizando 10 quartéis, sendo 7 do Comando Distrital de Operações de Socorro (CDOS) de Coimbra: AHBV (Associação Humanitário de Bombeiros Voluntários) de Miranda do Corvo com o Destacamento de Semide, CMB (Corporação Municipal de Bombeiros) da Lousã, AHBV de Serpins, AHBV de
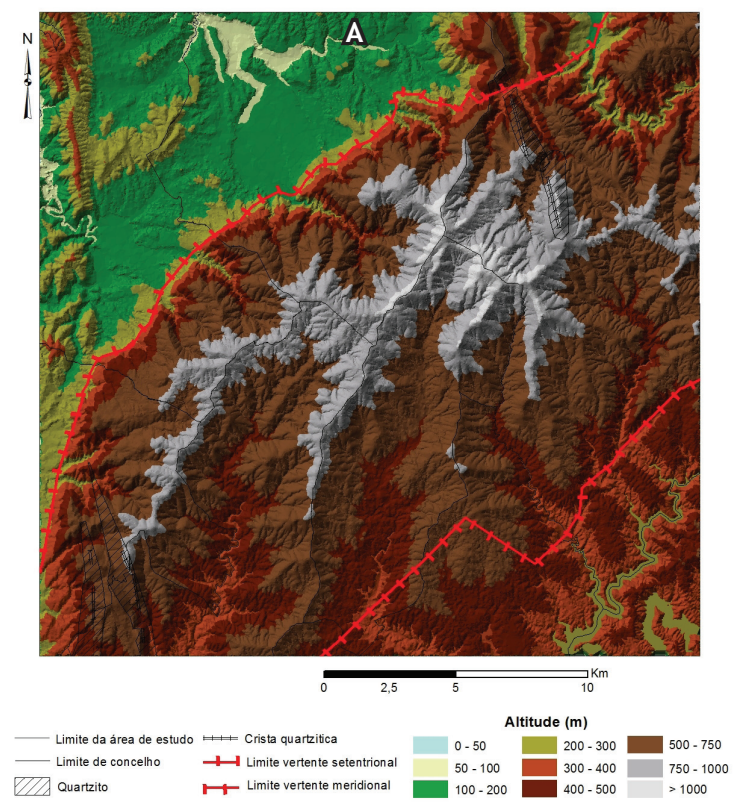

Gois com a Secção de Alvares e a AHBV de Penela, e 3 do CDOS de Leiria: AHBV de Figueiró dos Vinhos, AHBV de Castanheira de Pera e AHBV de Pedrogão Grande. Sete deles dependem de Associações Humanitárias e apenas um deles (CMB) é pertença da respetiva Câmara Municipal.

A fundação e distribuição geográfica dos Corpos de Bombeiros obedeceu inicialmente à ação esforçada de pessoas unidas por interesses e ideais comuns, das próprias comunidades locais, ou de algum nobre, com a finalidade de acautelar essas populações do concelho ou da área abrangente do local de residência.

Com a dispersão da população pelo território, foise começando a sentir dificuldade em acautelar as populações mais afastadas, o que levou a que alguns corpos de bombeiros tivessem criado secções destacadas como foi o caso de Semide, em Miranda do Corvo, e de Alvares, em Góis.

Outro aspeto que ressalta é a localização dos quarteis de bombeiros a cotas baixas (TABELA IV), o que assume bastante relevância no combate aos incêndios florestais, uma vez que a serra da Lousã se ergue abruptamente dos 200 até perto dos 900-1000 metros de altitude, funcionando como uma forte barreira à passagem de uma vertente para a outra da serra (fig.s 1 e 2 ).

Como os corpos de bombeiros se localizam a baixas altitudes (TABELA IV e fig. 2-A), com os da vertente setentrional (VS) a uma altitude média de $194 \mathrm{~m}$ e os da vertente meridional (VM) a $424 \mathrm{~m}$, e atendendo a que o ponto florestal mais alto, Altar do Trevim, está a 1 205m de altitude, os veículos têm de se deslocar para

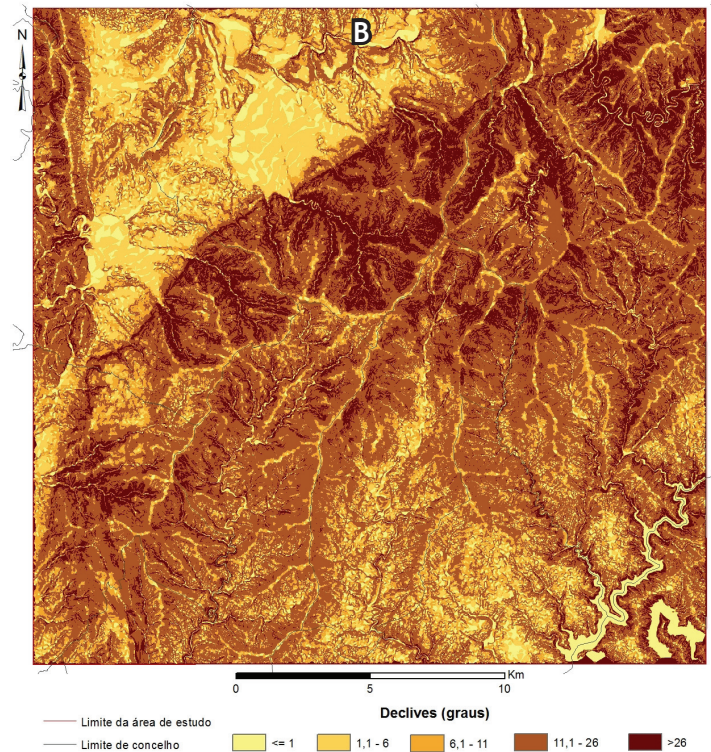

Fig. 1 - Serra da Lousã: A -Mapa hipsométrico e delimitação geomorfológica; B - Mapa de declives (F. Félix, 2014).

Fig. 1 - Lousã Mountain: A - Hypsometric map and geomorphological boundary; B - Slopes map (F. Félix, 2014). 
altas altitudes (os desníveis máximos são: VS-1011m e VM-781m), em movimentos ascendentes relativamente curtos e sinuosos, o que coloca entraves à velocidade dos carros de combate, já de si pesados e com os tanques cheios de água.

Os 10 quarteis de bombeiros existentes na serra da Lousã estão interligados entre si por 5 eixos principais, correspondentes a estradas nacionais e municipais, as quais apresentam percursos sinuosos, com destaque para a que atravessa a serra, o que aumenta o tempo de reposta dos bombeiros, comparativamente aos obtidos em estradas com traçados retilíneos.

$\mathrm{Na}$ análise da sinuosidade, enquanto indicador geométrico, verificamos que, apesar das diferentes tipologias de vias de comunicação, todas elas são afetadas por constrangimentos físicos ou urbanísticos que obrigam a que as estradas apresentem um traçado tortuoso (fig. 2), acarretando insuficiências, por vezes graves, na minimização dos tempos de deslocação e na penosidade das viagens (Souto, 2006).

A proeminência da sinuosidade salienta-se em todo o seu esplendor quando atravessamos a serra da Lousã, principalmente, na vertente setentrional. A área mais baixa $(\leq 215 \mathrm{~m})$, apresenta um índice de sinuosidade de 1,150 , ao passo que, na área mais alta $(>215 \mathrm{~m})$, o índice de sinuosidade é de 1,402 (F. Félix 2014)
Este bloco situado a cotas mais elevadas, condicionou a implementação de um traçado rodoviário que favoreça as deslocações, uma vez que a presença de diversos obstáculos topográficos obrigou a que a estrada fosse serpenteando na procura dos melhores locais para os transpor (Pina, 1997).

Por esse motivo, como bem referiu R. Almeida (2006), o poder de concentração de meios diminui drasticamente à medida que nos afastamos do quartel dos bombeiros, não só por estes se encontrarem afastados, mas também pelo sistema rodoviário sinuoso, que tende a dificultar a progressão dos meios terrestres. Por outro lado, os declives potenciam o desenvolvimento das chamas, pois à medida que os declives aumentam elas também aumentam de intensidade (TABELa II).

Por estas razões, é necessário um uso racional das forças de combate, homens e meios, especialmente nas áreas mais sensíveis, de modo a dispersá-las harmoniosamente pelo território, diminuindo as distâncias entre os possíveis locais de concentração das forças de combate e os pontos de ignição.

Assim, interessa-nos saber o número total de homens e de meios de combate a incêndios florestais, no sentido de relacionar o número de bombeiros e de meios terrestres de combate com a respetiva área municipal e, em especial, com os espaços silvestres (povoamentos e matos).

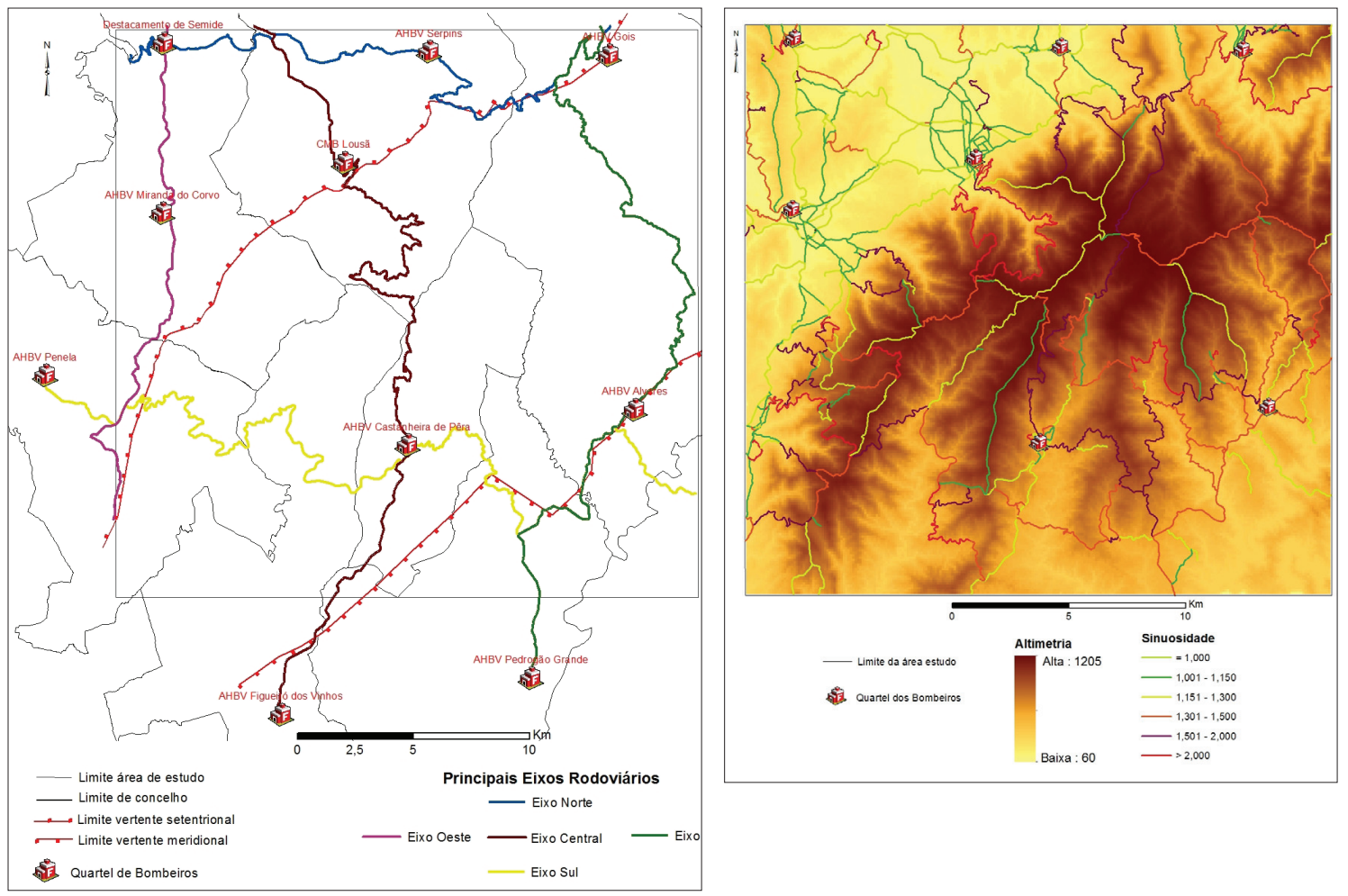

Fig. 2 - Serra da Lousã: A - Principais eixos rodoviários entre quartéis de bombeiros; B - Altimetria e sinuosidade do sistema rodoviário (F. Félix, 2014).

Fig. 2 - Lousã Mountain: A - Main roads between fire stations; B - altimetry and sinuous road system F. Félix, 2014). 
TABELA II - Classes de declives e suas condicionantes.

$T_{A B L E}$ II - Slope classes and its constraints.

\begin{tabular}{|c|c|c|c|}
\hline \multirow{2}{*}{\multicolumn{2}{|c|}{ Classes de declive }} & \multicolumn{2}{|c|}{ Condicionantes } \\
\hline & & Combate & Comportamento do fogo \\
\hline$<2 \%$ & $\leq 1^{\circ}$ & Área de infiltração máxima & Velocidade baixa \\
\hline $2-10 \%$ & $1,1-6^{\circ}$ & Praticáveis por pessoas e veículos normais & $\begin{array}{l}\text { Duplica a velocidade (Mcarthur, } 1968 \text { in B. Butler et al., } \\
\text { 2007; Viegas, 1989) }\end{array}$ \\
\hline $11-20 \%$ & $6,1-11^{\circ}$ & $\begin{array}{l}\text { Marcha só possível a passo, os veículos normais } \\
\text { apresentam algumas dificuldades }\end{array}$ & $\begin{array}{l}\text { Quadruplica a velocidade (Mcarthur, } 1968 \text { in B. Butler et } \\
\text { al., 2007; Viegas, 1989) }\end{array}$ \\
\hline $21-50 \%$ & $11,1-26^{\circ}$ & Praticáveis apenas por veículos todo o terreno & \\
\hline$>50 \%$ & $>26^{\circ}$ & $\begin{array}{l}\text { Marcha quase impossível, só veículos especiais } \\
\text { conseguem operar }\end{array}$ & Fogo Eruptivo (Viegas, 2006). \\
\hline
\end{tabular}

Fonte: Adaptado de L. Lourenço e A. Nave, 2006. Source: Adapted from L. Lourenço e A. Nave, 2006.

Os meios de combate disponíveis na serra da Lousã

Tendo em conta que a área de estudo tem 592,96km² (correspondendo aos concelhos da serra da Lousã), que em cerca de $87 \%\left(517,52 \mathrm{~km}^{2}\right)$ o solo apresenta uso florestal e que, por outro lado, a população residente nesses concelhos era, em 2011, de 54222 habitantes, torna-se necessário disponibilizar recursos humanos (quadro de ativos) e meios mecânicos terrestres para proteger dos incêndios florestais tanto esses 54222 habitantes, como $517,52 \mathrm{~km}^{2}$ de espaço com aptidão florestal. Para dar resposta a esse e a outros objetivos, os 8 Corpos de Bombeiros dos municípios que integram a serra da Lousã estão munidos com,655 elementos do quadro de ativo e 48 veículos terrestres de primeira intervenção (TABELA III), uma quantidade de recursos (humanos e materiais) que, estando bem distribuídos, parecem ser suficientes para defender a área em questão, embora com algumas limitações, pois se ocorrerem diversas ignições num curto período de tempo, isso levará à dispersão dos meios de combate, podendo pôr em causa não só a eficácia do ataque inicial, mas também a do ataque ampliado se vier a ser necessário.

Deste modo, em média, nos municípios da serra da Lousã, existe 1 bombeiro para 82,78 habitantes e por $1,58 \mathrm{~km}^{2}$ de área concelhia e $0,79 \mathrm{~km}^{2}$ de uso florestal do solo (TABELA IV) (F. Félix, 2014).

Por outro lado, cada meio terrestre de combate a incêndios é responsável pela defesa de 1 129,63 habitantes, e pela cobertura de $21,50 \mathrm{~km}^{2}$ de área municipal e de $10,78 \mathrm{~km}^{2}$ de floresta (F. Félix, 2014).

No entanto, quando procedemos à análise dessa distribuição em cada concelho, verificamos a existência de grandes desigualdades. Com efeito, enquanto em Castanheira de Pera existe um veículo de ATI por cada $10 \mathrm{~km}^{2}$, em Góis cada um deles tem mais de $60 \mathrm{Km}^{2}$ para proteger. Os municípios de Penela, Miranda do Corvo e Pedrógão Grande, situam-se entre 10 e $20 \mathrm{Km}^{2}$ e os de Lousã e Figueiró dos Vinhos entre 20 e $30 \mathrm{Km}^{2}$, pelo que o maior desequilíbrio diz respeito a Góis (F. Félix, 2014).

Todavia, tendo em conta que o combate aos incêndios florestais, se fará apenas em áreas onde o uso do solo é florestal, a situação apresenta ligeiras modificações, de entre as quais ressalta o agravamento do concelho de Góis. Neste contexto, a área a defender é menor em todos os concelhos, com Penela $\left(4,42 \mathrm{~km}^{2}\right)$ a passar para o primeiro lugar $\left(<5 \mathrm{~km}^{2}\right)$ e com a categoria seguinte, de 5 a $10 \mathrm{~km}^{2}$, a continuar ocupada com três municípios: Pedrogão Grande $\left(6,48 \mathrm{~km}^{2}\right)$, Castanheira de Pera $(8,40$ $\left.\mathrm{km}^{2}\right)$ e Miranda do Corvo $\left(8,54 \mathrm{~km}^{2}\right)$. Seguem-se-lhes, entre 10 e $15 \mathrm{~km}^{2}$, Figueiró dos Vinhos $\left(10,73 \mathrm{~km}^{2}\right)$ e Lousã $\left(14,25 \mathrm{~km}^{2}\right)$, destacando-se, pela negativa, o município de Góis (TABELA IV), com uma área crítica de $37,75 \mathrm{~km}^{2}$ por veículo ATI (F. Félix, 2014).

Deste modo, a serra da Lousã encontra-se bem abastecida de meios para fazer face aos incêndios florestais. Contudo, a sua distribuição pelo território, quando é analisada a uma escala mais local, comporta algumas carências e que tende a agravar-se se, aos meios existentes, adicionarmos a variável das acessibilidades, a qual condiciona a capacidade de deslocação dos meios para as manchas florestais e, por conseguinte, faz aumentar o tempo de resposta para a chegada aos locais de ignição.

De facto, tendo em conta o nível da disponibilidade de meios, a eficácia da primeira intervenção deveria ser maior, pois nem sempre foi conseguida, dado que arderam 9 655,55 hectares entre 2001 e 2013. Sabemos que " $A$ acessibilidade depende da proximidade e das condições de acesso" (R. Almeida, 2006), pelo que este factor não deverá ser descurado, tanto mais que tem contribuído fortemente para o insucesso da primeira intervenção, dadas as características específicas destes locais. 
$O$ declive enquanto elemento-chave na gestão do risco de incêndio florestal

Hoje existem vários índices de risco, como refere $A$. Ferreira (2010) “A avaliação das componentes de risco não é uma preocupação recente e sobre ela já vários autores (Chuvieco e Congalton, 1989; Lourenço, 1991b; Vettorazzi e Ferraz, 1998; Garcia et al. 1998; Strino et al., 2007; Saglam et al., 2008; Aranha, 2004, desenvolveram estudos, tanto em Portugal como em outros países".
"O desenvolvimento de um índice de risco implica a consideração de um conjunto de factores, nomeadamente os combustíveis, a topografia e a meteorologia" (A. Ferreira, 2010; Castro et al., 2002 e Muñoz, 2000), pelo que nos diversos modelos propostos, estão sempre presentes estas três variáveis: meteorologia, combustível e topografia.

No entanto, qualquer deles pode ser analisado sob diversas perspetivas e com diferentes ponderações. Assim, as condições meteorológicas poderão realçar

TABELA III - Áreas e efetivos, populacionais e operacionais, dos municípios da serra da Lousã.

TABLE III - Areas and effectives, population and operational, of the municipalities in the Lousã Mountain

\begin{tabular}{|c|c|c|c|c|c|c|c|c|c|c|c|}
\hline \multirow{3}{*}{ Concelho } & \multicolumn{3}{|c|}{ Concelho } & \multicolumn{2}{|c|}{ Área de Estudo } & & & \multicolumn{2}{|c|}{ Quadro } & \multicolumn{2}{|c|}{$\begin{array}{c}\text { Meios Terrestes } \\
\text { de ATI }\end{array}$} \\
\hline & \multicolumn{2}{|c|}{ Área total } & \multirow{2}{*}{$\begin{array}{l}\text { Pop. } \\
\text { Resid. } \\
2011 \\
\text { (hab.) }\end{array}$} & \multirow{2}{*}{$\begin{array}{l}\text { Área } \\
\text { total } \\
\left(\mathbf{k m}^{2}\right)\end{array}$} & \multirow{2}{*}{$\begin{array}{c}\text { Solo } \\
\text { Florestal } \\
\left(\mathbf{k m}^{2}\right)\end{array}$} & \multirow{2}{*}{\multicolumn{2}{|c|}{ Corpos de Bombeiros }} & \multirow{2}{*}{ き } & \multirow{2}{*}{$\begin{array}{l}\text { o } \\
3 \\
3 \\
\frac{0}{3}\end{array}$} & \multirow{2}{*}{$\begin{array}{l}V \\
L \\
C \\
I\end{array}$} & \multirow{2}{*}{$\begin{array}{l}V \\
F \\
C \\
I\end{array}$} \\
\hline & (ha) & $\left(\mathrm{Km}^{2}\right)$ & & & & & & & & & \\
\hline \multirow{2}{*}{ Miranda do Corvo } & \multirow{2}{*}{12637,8} & \multirow{2}{*}{126,38} & \multirow{2}{*}{13098} & \multirow{2}{*}{88,96} & \multirow{2}{*}{68,31} & \multirow{2}{*}{ AHBV Miranda Corvo } & Miranda do Corvo & 123 & \multirow{2}{*}{148} & 6 & \multirow{2}{*}{8} \\
\hline & & & & & & & Destac. Semide & 25 & & 2 & \\
\hline \multirow{2}{*}{ Lousã } & \multirow{2}{*}{13840,0} & \multirow{2}{*}{138,40} & \multirow{2}{*}{17606} & \multirow{2}{*}{111,38} & \multirow{2}{*}{85,51} & \multicolumn{2}{|l|}{ CMB da Lousã } & 94 & \multirow{2}{*}{146} & 4 & \multirow{2}{*}{6} \\
\hline & & & & & & \multicolumn{2}{|l|}{ AHBV de Serpins } & 52 & & 2 & \\
\hline \multirow{2}{*}{ Góis } & \multirow{2}{*}{26330,2} & \multirow{2}{*}{263,30} & & & & & Góis & 28 & & 3 & \\
\hline & & & 4200 & 150,50 & 101,00 & AIIOV de vols & Secção Alvares & 28 & 50 & 1 & 4 \\
\hline Penela & 13480,0 & 134,80 & 5983 & 50,53 & 44,15 & AHBV de Penela & & 92 & 92 & 10 & 10 \\
\hline Figueiró dos Vinhos & 17344,0 & 173,44 & 6169 & 67,69 & 64,37 & AHBV de Figueiró dos & Vinhos & 75 & 75 & 6 & 6 \\
\hline Castanheira de Pera & 6677,5 & 66,78 & 3191 & 66,78 & 58,82 & AHBV de Castanheira & de Pera & 66 & 66 & 7 & 7 \\
\hline Pedrógão Grande & 12874,8 & 128,75 & 3915 & 49,32 & 45,37 & AHBV de Pedrogão $\mathrm{Gr}$ & ande & 72 & 72 & 7 & 7 \\
\hline Total & 103184,3 & 1031,85 & 54222 & 592,96 & 517,53 & $8+2$ secções $=10$ qua & téis & & & & \\
\hline
\end{tabular}

Fonte dos dados: Censos 2011, CAOP 2012; Corine Land Cover 2006, Quadro de Homens e Meios Terrestres de Combate a Incêndios Florestais (inventário enviado a cada corporação de Bombeiros). Data Source: Census 2011, CAOP 2012; Corine Land Cover 2006, Table of Men and Land Means for Forest Fires Combat (inventory sent to each Fire Corporation).

TABELA IV - Distribuição de recursos (Bombeiros e Veículos), por habitantes e superfícies.

TABLE IV - Resource allocation (Firefighter and vehicles) by people and areas.

\begin{tabular}{|c|c|c|c|c|c|c|c|c|c|}
\hline \multirow{3}{*}{ Concelhos } & \multirow{3}{*}{ Corpos de Bombeiros } & \multirow{3}{*}{$\begin{array}{l}\text { Ano de } \\
\text { Fundação }\end{array}$} & \multicolumn{7}{|c|}{ Índices } \\
\hline & & & \multicolumn{3}{|c|}{ Bombeiros } & \multicolumn{4}{|c|}{ Meios terrestres de ATI } \\
\hline & & & $\begin{array}{l}\text { Altitude } \\
\text { (m) }\end{array}$ & $\begin{array}{l}\text { Por } \\
\text { hab. }\end{array}$ & $\begin{array}{l}\text { Por } \\
\mathrm{km}^{2}\end{array}$ & $\begin{array}{l}\text { Por } \mathrm{km}^{2} \text { de } \\
\text { Floresta }\end{array}$ & Por hab. & $\begin{array}{l}\text { Por } \\
\mathrm{km}^{2}\end{array}$ & $\begin{array}{l}\text { Por } \\
\mathrm{km}^{2} \text { de } \\
\text { Flor. }\end{array}$ \\
\hline \multirow{2}{*}{ Miranda do Corvo } & AHBV Miranda do Corvo & 1946 & 104 & \multirow{2}{*}{88,50} & \multirow{2}{*}{0,85} & \multirow{2}{*}{0,46} & \multirow{2}{*}{1637,25} & \multirow{2}{*}{15,80} & \multirow{2}{*}{$8,54 \downarrow$} \\
\hline & Destacamento de Semide & 2008 & 185 & & & & & & \\
\hline \multirow{2}{*}{ Lousã } & CMB da Lousã & 1904 & 173 & \multirow{2}{*}{120,59} & \multirow{2}{*}{0,95} & \multirow{2}{*}{0,59} & \multirow{2}{*}{2934,33} & \multirow{2}{*}{23,07} & \multirow{2}{*}{$14,25 \uparrow$} \\
\hline & AHBV de Serpins & 1983 & 110 & & & & & & \\
\hline Góis & AHBV Góis & 1956 & 200 & 76,07 & 4,70 & 2,70 & 1065,00 & 65,83 & $37,75 \uparrow$ \\
\hline Penela & AHBV Penela & 1987 & 334 & 65,03 & 1,47 & 0,48 & 598,30 & 13,48 & $4,42 \downarrow$ \\
\hline Figueiró dos Vinhos & AHBV Figueiró dos Vinhos & 1980 & 250 & 82,25 & 2,31 & 0,86 & 1028,17 & 28,91 & $10,73 \downarrow$ \\
\hline Castanheira de Pera & AHBV Castanheira Pera & 964 & 375 & 48,35 & 1,01 & 0,89 & 455,86 & 9,54 & $8,40 \downarrow$ \\
\hline Pedrógão Grande & AHBV Pedrogão Grande & 1935 & 431 & 54,38 & 1,79 & 0,63 & 559,29 & 18,39 & $6,48 \downarrow$ \\
\hline \multicolumn{3}{|l|}{ Serra da Lousã } & & 82,78 & 1,58 & 0,79 & 1129,63 & 21,50 & 10,78 \\
\hline
\end{tabular}

Fonte dos Dados: Censos 2011, CAOP 2012; Corine Land Cover 2006, Quadro de Homens e Meios Terrestres de Combate a Incêndios Florestais (inventário enviado a cada corporação de Bombeiros). Data Source: Census 2011, CAOP 2012; Corine Land Cover 2006, Table of Men and Land Means for Forest Fires Combat (inventory sent to each Fire Corporation). 
a temperatura máxima, a temperatura média, a temperatura prevista para o dia seguinte, a humidade mínima relativa do ar, o rumo e velocidade do vento. Por sua vez, a vegetação, que constitui o combustível, pode ser analisada segundo a sua distribuição vertical e horizontal, a densidade, a dimensão, a quantidade ou carga, a humidade do combustível, a altura da copa, a combustibilidade e a percentagem de combustíveis finos. Por último a topografia, que representa as formas do relevo, a qual é frequentemente abordada em função da sua forma, altitude, declive e exposição das vertentes.

Numa perspetiva simplista, contudo rigorosa, podemos afirmar que para arder é necessário que as condições atmosféricas o proporcionem. Como referiu L. Lourenço (1988) “as condições sinópticas são preponderantes para a explicação dos incêndios florestais. Existe, efectivamente, uma relação directa entre determinados tipos de tempo e a ocorrêncua de incêndios florestais", pelo que a meteorologia estará sempre presente.

Por outro lado, a vegetação também tem de estar presente, uma vez que corresponde ao combustível. Segundo Abhinnet et al. (1996), é o factor mais importante na determinação de risco de incêndio porque sem combustível florestal os incêndios não podem ocorrer, ou seja, "[...] even thought the fire environment may be favourable, forest fires cannot occur unless there is inflammable material".

Deste modo, estas duas variáveis, meteorologia favorável e vegetação, têm de estar simultaneamente presentes para que possa ocorrer um incêndio florestal. Por outro lado, a topografia é o factor que influência significativamente o comportamento do fogo, como refere Abhineet et al. (1996) "The fire behaviour is largely controlled by topography", especialmente em resultado da forma dos declives.

Mcarthur (1968) in B. Butler et al. (2007), sugere que os declives podem afetar significativamente a taxa de propagação do incêndio, em especial, imediatamente após a sua ignição. Ele sugere que, quando comparado com terreno plano, a taxa de propagação da frente de fogo vai aumentar duas vezes quando os declives forem de $10^{\circ}$ e quatro vezes, quando passam a $20^{\circ}$. Segundo Viegas (1989), a velocidade de propagação duplica, regra geral, em cada $10 \%$ de aumento do declive.

Na presença de declives muito acentuados, um incêndio pode acelerar continuamente desde o sopé até à linda de cumeada, atingindo velocidades muito elevadas, 5 a $6 \mathrm{~km} / \mathrm{h}$. A partir de $30^{\circ}$ de declive, a relação do declive com a velocidade é quase exponencial, pelo que deve ser dada especial atenção a declives superiores a este valor (X. Viegas, 2006).
Contudo, para além de influenciarem diretamente o incêndio, os declives também influenciam indiretamente o comportamento do incêndio ao dificultar o seu combate. Com efeito, além de contribuírem para a formação de ventos locais, que influenciam diretamente a progressão das chamas, em particular no sentido ascendente, também interferem no combate direto, pois quanto maior for o declive, maior será a dificuldade de deslocação e de chegada à frente de combate, bem como da própria atuação dos meios de combate que, muitas vezes, ficam incapacitados de um ataque direto ao incêndio (A. Vasconcelos, 2013).

Tal já era percetível em alguns dos estudos realizados, nomeadamente, num que pretendeu investigar as principais causas humanas adjacentes à ocorrência e propagação do fogo florestal na região Centro, onde abordou, entre outras, as "Variáveis de ordem física e operacional (maior altitude máxima e maior distância ao quartel de bombeiros)" (L. Lourenço, et al., 2001), tendo realçado que "Os fatores físicos podem também contribuir de forma indireta para os incêndios florestais, [...] Um excelente exemplo disso, é a forma como o relevo vigoroso e acidentado, vai agravar o risco de incêndio, não só porque ao proporcionar elevadas diferenças de altitude com declives consideráveis, mas também porque imprime um traçado sinuoso às estradas, o qual condiciona a velocidade máxima de circulação rodoviária, aumentando o tempo necessário para percorrer as distancias entre os quartéis de bombeiros e os pontos mais afastados da sua esfera de atuação, já de si longos, mas a assumirem maior significado quando se trata de combate a incêndios florestais, e, muito em especial, do primeiro "ataque" a fogos nascentes" (L. Lourenço, et al., 2001).

No combate aos incêndios florestais é, pois, fundamental que o ataque inicial a incêndios nascentes seja eficiente, para evitar que os pontos de ignição evoluam para grandes incêndios, com extensas frentes de fogo e focos secundários. Para que tal possa acontecer, deve dar-se especial atenção a locais com fortes declives (M. Carmo et al., 2011), uma vez que a presença de combustíveis nessas áreas facilita o desenvolvimento de grandes incêndios florestais, que se propagarão com maior rapidez e cujos danos facilmente atingirão maiores proporções do que os registados nos incêndios que se desenvolvem em declives suaves, pelo que deverão ser alvo de estratégias específicas, pois necessitam de uma resposta de intervenção ainda mais rápida que a habitual, não só pela velocidade de propagação dos incêndios em fortes declives, mas também pelas condicionantes que impõem à deslocação dos meios terrestes de combate.

Deste modo, as áreas declivosas apresentam uma elevada sensibilidade ou fragilidade, entendidas como "o nível e a extensão dos danos que os elementos expostos podem sofrer, os quais estão associados às características 
intrínsecas dos elementos expostos, bem como ao seu grau de proteção" (Cutter, 2011 in L. Lourenço, 2014), pelo que se torna necessário ajustar os meios disponíveis e os respetivos tempos de resposta, de modo a minimizar as consequências dos incêndios uma vez que, pelas referidas "características intrínsecas dos elementos expostos", estes espaços necessitam de um ataque ainda mais atempado, inferior a 20 minutos, ou seja "o seu grau de proteção" deverá ser maior, caso contrário os danos serão visíveis mais rapidamente, evoluindo para incêndios incontroláveis.

Operacionalidade dos meios de combate a incêndios florestais nas áreas de montanha. O exemplo da Serra da Lousã

Nos países do sul da Europa é importante falar das florestas, não só pela área de território que ocupam, mas também devido ao valor económico dos seus produtos, os serviços ambientais que proporcionam e, ainda, pelos riscos que comportam, com especial relevância para o de incêndio florestal (J. S. Pereira, 2013).

Conforme referem S. Oliveira et al., (2014) “A gestão de incêndios florestais é um dos principais desafios que a Europa Mediterrânea enfrenta, incluindo Portugal, tanto no contexto da segurança das populações como em termos da proteção e conservação dos recursos naturais".

Face a este cenário, torna-se urgente analisar a vulnerabilidade de cada território, tendo em conta as suas especificidades, de modo a que se possam delinear medias e tomar ações não só de combate aos incêndios (reativas), mas também e acima de tudo, de prevenção (proativas), "orientadas de acordo com a vulnerabilidade de cada área, contribuindo para uma gestão mais eficiente dos recursos disponíveis" (S. Oliveira et al., 2014), uma vez que "[...] sem uma boa coordenação e sem um bom conhecimento das características do terreno (topografia e vegetação) e da rede viária (tipo e estado), a utilização dos recursos fica muitas vezes aquém das suas reais potencialidades" (J. Aranha, 2004).

Com efeito, é preciso saber ler o território, é necessário conhecer as características do terreno, saber analisar "diversos parâmetros naturais e antrópicos, tais como a densidade populacional, a localização de edifícios, que representam a exposição e a sensibilidade dos elementos naturais e humanos aos incêndios florestais" (S. Oliveira et al., 2014) e, também, a rede viária, de modo a que se possa estimar o grau de acessibilidade a um determinado local, a partir de um outro (S. Geertman et al., 1995), a influência da sinuosidade rodoviária no tempo de deslocação para uma primeira intervenção eficaz (F. Félix, 2014), pois, de outra forma, os recursos disponíveis ficam muitas vezes impossibilitados de dar o seu real contributo no combate aos incêndios florestais.
Como é sabido, todos os incêndios florestais começam por ser pequenos fogos. As condições atmosféricas e a disponibilidade de combustível (vegetação) possibilitam a existência de um grande o número de ignições e os declives potenciam a dimensão das áreas ardias, tornando difícil o seu combate, quer pelo número de ocorrências quer pela severidade que os incêndios podem assumir.

Ora, tendo em conta o quantitativo de corpos de bombeiros existentes em Portugal, bem como os meios de combate existentes, como é que se pode explicar que pequenas ignições derivem para incêndios florestais incontroláveis? Como referiu P. Ribeiro (2002) “Em Portugal continental existem 444 corpos de bombeiros dos quais $30 \%$ estão sediados na franja do Litoral, logo menos sensível à problemática dos incêndios Florestais". Por sua vez em 2009, A. Amaro refere a existência, no continente, de um "número total de 437 corporações de bombeiros, divididas por 413 Corpos de Bombeiros Voluntários/Associativos, [...]".

Apesar de Portugal ter mais Corpos de Bombeiros do que concelhos, a sua distribuição e localização não potencia o combate aos incêndios florestais já que a sua maioria funciona no regime de voluntariado, que sendo cada vez menos atrativo, se traduz num número reduzido de elementos do quadro ativo, onde cada vez é mais difícil escalar turnos, em especial nas áreas montanhosas do interior, que continuam a ver sair as suas gentes em busca de melhores condições de vida, o que coloca um grave problema operacional que, a continuar assim, fará com que daqui a alguns anos o sistema entre em colapso.

De facto, Rui Almeida (2006) já evidenciava que “ $A$ distribuição dos meios de extinção de incêndios florestais em Portugal está mais relacionada com a distribuição da população do que com a distribuição das áreas florestais, o que constitui um problema operacional", uma vez que se "aumenta a distância dos Corpos de Bombeiros às áreas florestais, e se temos uma menor densidade de meios por hectare de floresta, aumentamos a probabilidade de insucesso da $1^{a}$ intervenção".

Com efeito, a dispersão de meios diminui drasticamente à medida que nos afastamos do quartel dos bombeiros, "diminuindo a relação entre área florestal e meios disponíveis, aumentam as dificuldades na capacidade de concentração de meios". Por outro lado, sabendo-se que os quartéis de bombeiros se localizam nas malhas urbanas, afastados das manchas florestais, a "criação de corpos de bombeiros profissionais para combate a incêndios florestais devem seguir uma lógica de prioridade para as zonas mais deficitárias em termos de voluntários e fugir ao facilitismo de os estabelecer junto das grandes zonas urbanas, onde existem já elevadas concentrações de meios de extinção" (R. Almeida, 2006). 
Deste modo, parece que é o próprio sistema de combate que se encontra desajustado. Como referem F. Tedim et al., (2014) a estratégia de combate assenta num "modelo demasiado rígido. Não há margem de manobra das organizações locais para decidirem o que fazer. Por exemplo, no passado, os corpos de bombeiros eram autónomas e faziam frequentes saídas do quartel que funcionavam como vigilância. Hoje, para os carros saírem do quartel, têm de comunicar ao Centro Distrital de Operações e Socorro (CDOS) e obter autorização. [...] os planos são impostos por regulamentação nacional, não prevendo a adaptação às realidades locais, o que dificulta e fragiliza a sua aplicação".

São bem conhecidas as limitações na deteção e localização de alguns incêndios florestais, sendo geralmente visíveis quando as colunas de fumo são significativas. Apesar de toda a estrutura operacional de deteção, fixa e móvel, os dados do ICNF (2012) confirmam que o alerta é maioritariamente dado por populares. Ora, se tivermos em conta o despovoamento das áreas de montanha do interior do país, onde a dimensão das áreas ardidas atinge o seu apogeu, as dificuldades para a deteção e ativação dos meios de combate serão ainda maiores, bem como as dificuldades que os meios terrestres de combate enfrentam para se deslocar dos quartéis de bombeiros, situados na malha urbana, a cotas baixas, paras as manhas florestais, por caminhos que tendem a ser sinuosos, aumentando o tempo de deslocação e com este o tempo de resposta da $1 .^{\mathrm{a}}$ intervenção.

Deste modo, "Qualquer intervenção dos Bombeiros no combate aos incêndios florestais implica necessariamente a deslocação dos meios humanos e mecânicos para as áreas florestais, cujos acessos e caminhos, pela sua própria natureza, apresentam dificuldades acrescidas à progressão de homens e máquinas, com o objetivo do ataque inicial: projetar, sobre o ponto de ignição, no mais curto espaço de tempo possível, a quantidade de água necessária $e$ suficiente para a extinção do mesmo, antes que ele assuma maiores proporções" (ENB, 2001 in F. Félix, 2014).

As acessibilidades referem-se à capacidade de alcançar ou ser alcançado por bens e serviços. Existem muitos fatores que afetam as acessibilidades, a qualidade das mesmas, o grau de cobertura, o tipo de transporte e a própria mobilidade, movimento físico/mecânico que é gravemente afetado por uma topografia irregular, com relevos acidentados, típica de áreas de montanha, agravada pelo transporte de tanques cheios de água, que necessitam de uma estratégia e planeamento ajustados a essa realidade territorial (Dalvi e Martin, 1976; Litman, 2008)

Neste contexto, "O tempo de resposta, depende da acessibilidade e disponibilidade de meios. A acessibilidade depende da proximidade e das condições de acesso. A disponibilidade depende do nível de empenhamento dos recursos e do número de recursos" (R. Almeida, 2006).
Tendo em conta que as disposições operacionais em vigor visam "Garantir o ATI, como uma intervenção organizada e integrada, sustentada por um despacho inicial, até 2 (dois) minutos depois de obtida a localização do incêndio, de forma musculada e consistente e em triangulação, de meios terrestres de combate a incêndios florestais provenientes dos 3 (três) Corpos de Bombeiros (CB) mais próximos do local do incêndio, se disponíveis" (ANPC, 2012), isso deve permitir colocar o primeiro meio de intervenção operacional, no local do incêndio, até 20 (vinte) minutos depois do despacho inicial.

O valor de 20 minutos foi definido pela taxa de esforço que uma equipa conjunta de 5 homens consegue produzir, levando ao controlo e extinção do foco de incêndio, ou seja, se chegarem depois dos 20 minutos, o foco de incêndio já evoluiu, tomando proporções em que uma equipa de cinco homens não o consegue controlar e debelar, tendo que haver reforço com o empenho de mais homens e meios.

Contudo, "O esforço utilizado depende da disponibilidade dos recursos e depende das condições dos recursos. As técnicas usadas dependem do conhecimento, da organização e da disponibilidade de meios" (R. Almeida, 2006), pelo que em todo este processo, a eficácia da primeira intervenção é fortemente influenciada pelo tempo de resposta, que é dado pelo tempo de deslocação, o qual, por sua vez, é influenciado pelos meios existentes, humanos e mecânicos, pelas características dos mesmo e pelo desenho das estradas, o qual é muito influenciado pelo relevo, pelo que estes fatores são aspetos-chave, que não podem deixar de ser tidos em linha de conta numa gestão integrada do risco de incêndio florestal.

\section{A influência da sinuosidade das estradas no ataque inicial aos incêndios florestais na serra da Lousã}

Como já foi referido anteriormente, a serra da Lousã herdou e continua a apresentar um sistema rodoviário bastante débil e sinuoso, o que complica o combate aos incêndios florestais.

A sinuosidade rodoviária traduz a ratio existente entre a distância real ou observada (DO) e a distância ideal ou expectável (DE). Numa análise geométrica o elemento curva, é aquele que no plano horizontal acarreta mais condicionantes negativas na velocidade. A sinuosidade rodoviária será o somatório dos seus elementos (retas e curvas) e a sua sequência ao longo de toda a extensão do percurso que vai ligar dois pontos $(A-B)$, e em que o perfil longitudinal poderá obrigar a subidas e descidas, visto que poderão estar a altitude diferentes, agravando a velocidade de deslocação.

Deste modo, alguns autores, como P. Rautela et al., (2007), para além da análise geométrica, adicionam ao índice de sinuosidade o gradiente de declives, pois referem que a 
cada ponto de início e de fim está associado um valor de cota (altitude), pelo que o gradiente de declives será o inverso da tangente da diferença entre estes dois pontos, independente do sentido de deslocação, a dividir pela distância expectável, que nos dá o valor do gradiente de declives em graus (fig. 3). Estes fatores, comprimento do raio de curva e perfil topográfico, terão uma influência potencial quando combinados.

No índice de sinuosidade rodopiara os valores próximos a 1,0 indicam que a estrada tende a ser retilínea. Se o valor da sinuosidade for igual a 1,5 significa que, em média, qualquer viagem efetuada por esse percurso tem uma extensão $50 \%$ superior ao caminho em linha reta (fig.4). Uma estrada com um percurso fortemente

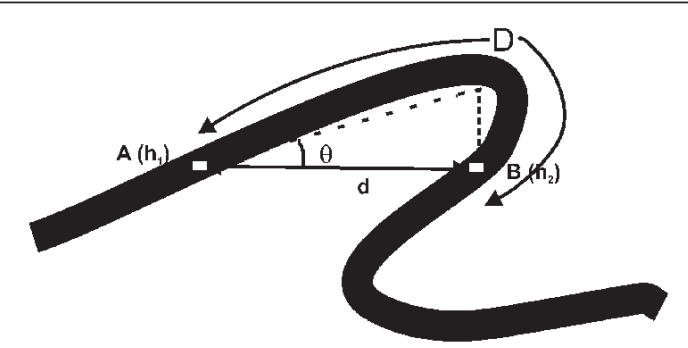

Definição do índice de sinuosidade $(\mathrm{SI})=\mathrm{D} / \mathrm{d}$. Gradiente de declives $\theta=\tan ^{-1}\left(\left(\left|h_{1}-h_{2}\right|\right) / \mathrm{d}\right)$. D - Distância Observada; d - Distância Expectável; $A_{h 1}$ - Cota do ponto de início; $B_{h 2}$ Cota do ponto do fim

Fig. 3 - Índice de sinuosidade e gradiente de declives (Fonte: P. RAUTELA et al., 2007).

Fig. 3 - Sinuosity index and slope gradient (Source: P. RAUTELA et al., 2007). acidentado, como é o caso de estradas que atravessam montanhas, o índice de sinuosidade pode mesmo ser igual a 4 (V. Govan, 2012).

No sentido de verificar o aumento da vulnerabilidade das áreas florestais em função dos valores dos diferentes tempos de deslocação/resposta, entre as variáveis descritas no Guia Técnico do Plano Municipal de Defesa da Floresta Contra Incêndios (2012), procedemos à análise da rede viária, através da construção de linhas isócronas relativas aos tempos de deslocação, a partir dos locais onde estão estacionadas as equipas de $1 .^{\mathrm{a}}$ intervenção, tendo por base os valores médios por veículo (VFCI/VRCl) e para cada tipo de via, disponibilizados pelo ICNF (TABELA V)

Utilizando como referência as estradas municipais, visto que são as mais representativas na nossa área de estudo, um $\mathrm{VFCl}$ ou um $\mathrm{VRCl}$, a uma velocidade média de $33 \mathrm{~km} / \mathrm{h}$, consegue percorrer $11 \mathrm{~km}$ em 20 minutos. Utilizando este valor como referência foram realizados buffers de com raios $11 \mathrm{~km}$ a partir dos quarteis de bombeiros (fig. 5).

Assim, considerando a distância em linha reta, toda a serra, a nossa área de estudo, estaria coberta no tempo de 15 minutos, já que só uma área mínima a sudoeste se encontra a 20 minutos (fig. 5).

Contudo, o combate aos incêndios florestais implica a deslocação rápida de meios até ao ponto de ignição. A rapidez da intervenção tem evoluído muito desde os tempos de antanho, em que as bombas eram puxadas primeiro pelo homem e depois por cavalos, até aos dias hoje, em que são transportadas em veículos destinados a circular em estradas. "The protection of the forest demands speed in putting out fires and speed in these days of motor vehicles means roads" (C. Buck, 1936).

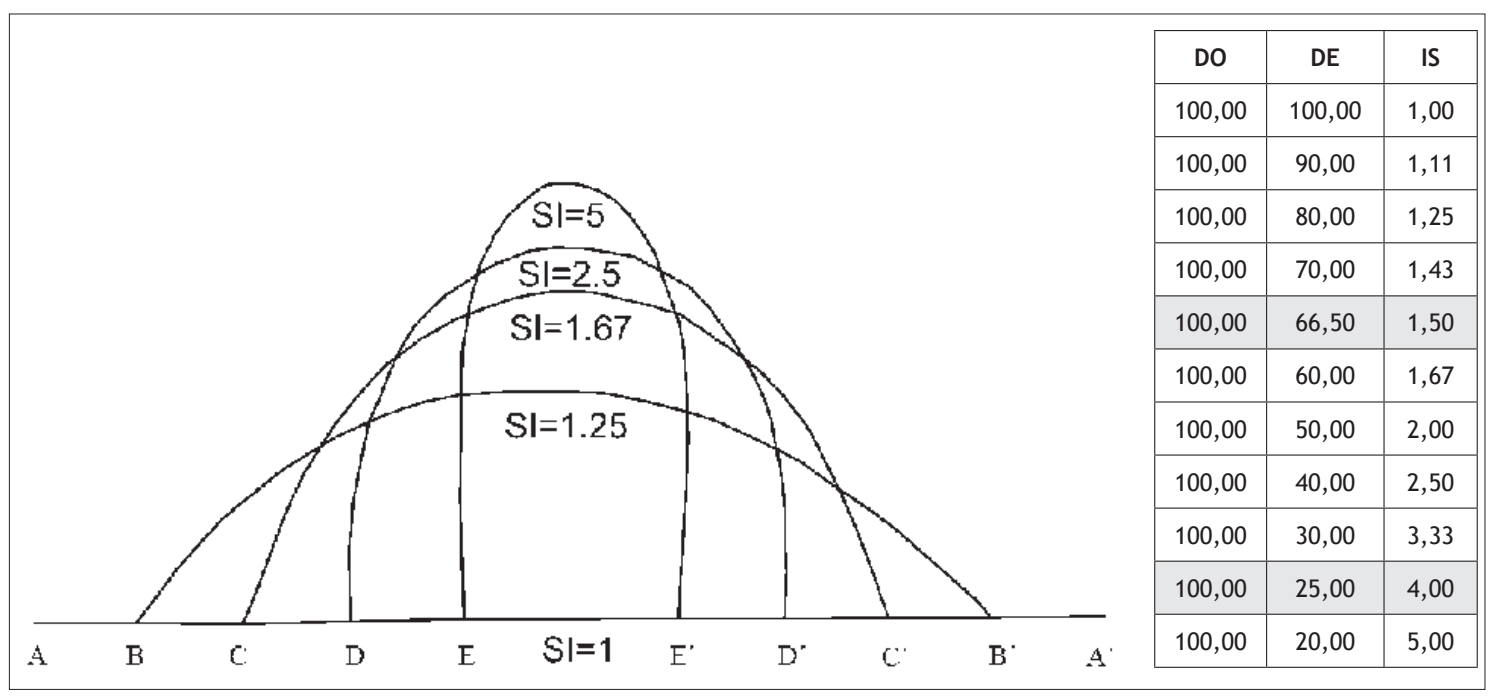

Fig. 4 - Diagrama esquemático representando aumento do índice de sinuosidade com o aumento da curvatura de um percurso de uma determinada estrada (Fonte: Adaptado de P. RAUTELA et al., 2007 in F. Félix, 2014).

Fig. 4 - Scheme representing an increase in the sinuosity index with increased curvature of a path in a given road (Source: Adapted from P. RAUTELA et al., 2007 in F. Félix, 2014). 
Ora, tendo presente as condicionantes físicas de um espaço de montanha, a circulação dos veículos depara-se com uma missão difícil de conseguir, desde logo pela sinuosidade rodoviária, resultante da diferença de cotas que influenciam o traçado, contribuindo para uma geometria curva que afetará a velocidade base de circulação, aumentando o tempo de resposta (fig. 6). "A área baixa ( $<=215 \mathrm{~m}$ ), apresenta um índice de sinuosidade de 1,150 , ao passo que, na área alta (> 215m), o índice de sinuosidade é de 1,402. Entre as diferentes hierarquias de vias não se verificam diferenças significativas quando confrontadas com o respetivo relevo. Exemplo disso é o trajeto da Lousã em direção a Castanheira de Pera, com ambas estradas, N236 e M555, a apresentarem índices de sinuosidade rodoviária superiores a 2,0" (F. Félix, 2014) (fig. 2).

TABELA V - Valores indicativos da velocidade média para uma viatura de combate a incêndios florestais, tipo $\mathrm{VFCl} / \mathrm{VRCl}$, por tipo de via e distância percorrida em ATI.

TABLE V - Indicative of the average speed for a forest fires fighting vehicle, type $\mathrm{VFCl} / \mathrm{VRCl}$, and by type of road and distance traveled in ATI.

\begin{tabular}{|c|c|c|c|c|}
\hline \multicolumn{3}{|c|}{ Tipo de Via } & $\begin{array}{l}\text { Velocidade } \\
\text { Média }\end{array}$ & $\begin{array}{l}\text { Distância em } \\
\text { ATI (20 min) }\end{array}$ \\
\hline \multicolumn{3}{|c|}{ Itinerário Principal } & $80 \mathrm{Km} / \mathrm{h}$ & $26,67 \mathrm{Km}$ \\
\hline \multicolumn{3}{|c|}{ Estrada Nacional } & $45 \mathrm{Km} / \mathrm{h}$ & $15,00 \mathrm{Km}$ \\
\hline \multicolumn{3}{|c|}{ Estrada Municipal } & $33 \mathrm{Km} / \mathrm{h}$ & $11,00 \mathrm{Km}$ \\
\hline \multirow{3}{*}{$\begin{array}{l}\text { Outras } \\
\text { Vias }\end{array}$} & \multirow{3}{*}{ 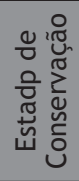 } & Bom & $27,5 \mathrm{Km} /$ & $9,17 \mathrm{Km}$ \\
\hline & & Médio & $19,0 \mathrm{Km} / \mathrm{h}$ & $6,63 \mathrm{Km}$ \\
\hline & & Mau & $11,0 \mathrm{Km} / \mathrm{h}$ & $3,67 \mathrm{Km}$ \\
\hline
\end{tabular}

Fonte: Adaptado de DUDEF, 2012. Soure: Adapted from DUDEF, 2012.

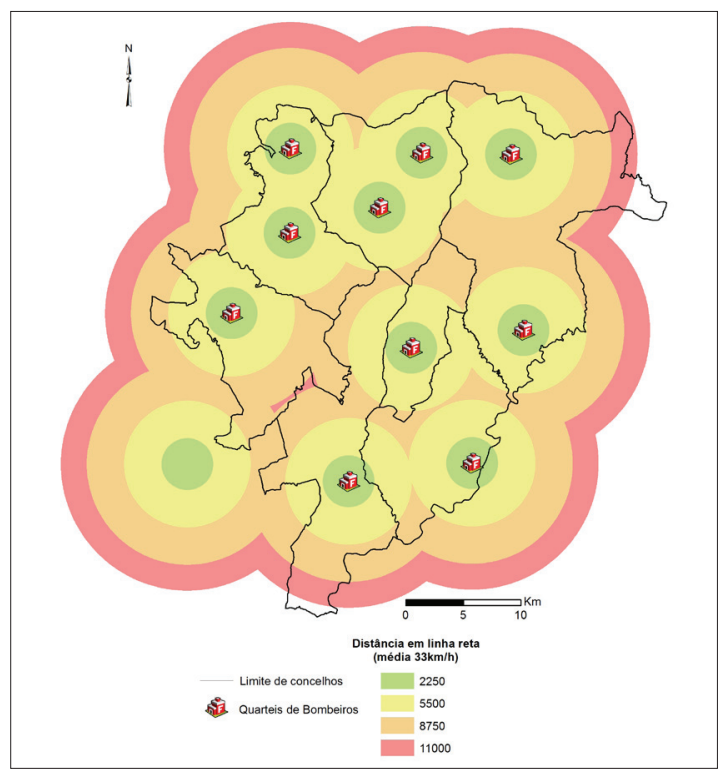

Fig. 5 - Mapa com tempos de deslocação teóricos, em linha reta (F. Félix, 2014).

Fig. 5 - Theoretical travel time's map, in a straight line (aerial) (F. Félix, 2014).
Assim, em vez de uma análise em linha reta, se tivermos em conta as especificidades do traçado da estrada, designadamente em termos da sua geometria, o cenário altera-se fortemente (TABELA VI). Logo à partida, nota-se a existência de áreas florestais, servidas por estradas, que se encontram a mais de 20 minutos (cerca de 10\%) do quartel dos bombeiros, tanto a nordeste como a sudoeste. Do mesmo modo, as áreas florestais servidas por estradas que distam entre 15 e 20 minutos dos quartéis, também ganham grande relevância (cerca de 12\%) (F. Félix, 2014).

0 exemplo mais flagrante é o da existência de áreas, no município de Góis, em que em termos de distância em linha reta estão dentro do raio dos 5 minutos, mas que devido à circulação se efetuar por estrada, passam a

TABELA VI - Distribuição dos lanços de estrada em função dos diferentes tempos de deslocação, a partir dos quartéis de bombeiros.

TABLE VI - Distribution of road links due to the different travel times, from the fire stations.

\begin{tabular}{|c|c|c|c|}
\hline $\begin{array}{l}\text { Tempos de } \\
\text { deslocação }\end{array}$ & $\begin{array}{l}\text { Extensão de } \\
\text { estrada (m) }\end{array}$ & \multicolumn{2}{|c|}{$\%$} \\
\hline 1-5 min. & 199159,04 & 27,20 & \multirow{3}{*}{78,17} \\
\hline 6-10 min. & 226047,85 & 30,88 & \\
\hline $11-15 \mathrm{~min}$. & 147089,36 & 20,09 & \\
\hline $16-20 \mathrm{~min}$. & 87476,20 & 11,95 & \multirow{2}{*}{21,83} \\
\hline$\geq 20 \mathrm{~min}$. & 72320,45 & 9,88 & \\
\hline Total & 732092,91 & & 100,00 \\
\hline
\end{tabular}

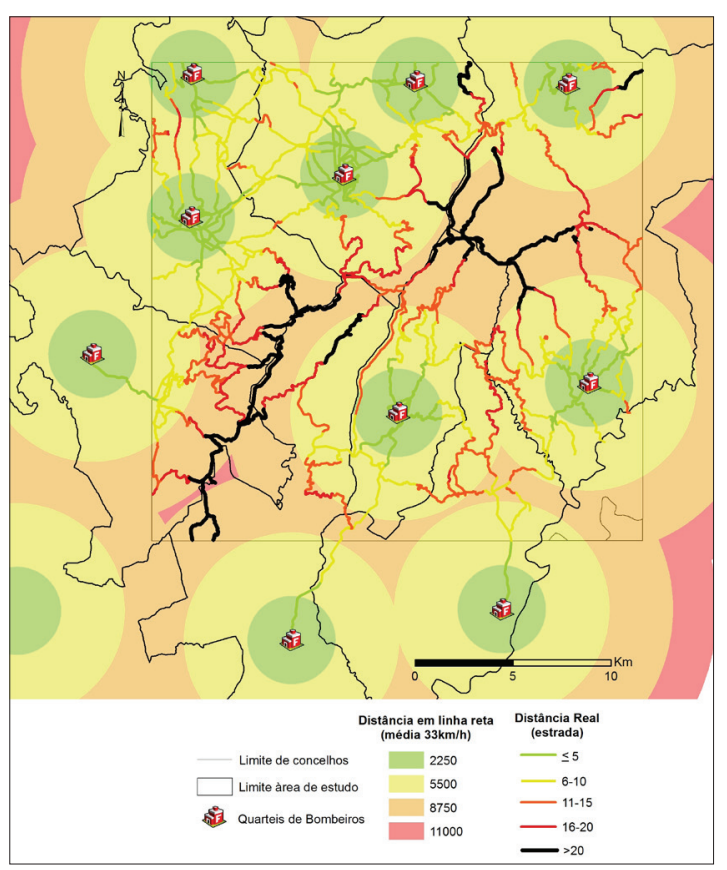

Fig. 6 - Mapa e tempos de deslocação, em linha reta e por estrada (F. Félix, 2014).

Fig. 6 - Travel time's map, in a straight line (aerial) and by road (real distance) (F. Félix, 2014). 
situar-se entre 15 e 20 minutos. Deste modo, a área de cobertura em que cada quartel de bombeiros consegue atuar dentro dos 20 minutos, bem como a dos outros locais que ficam fora deste raio de atuação atempada, é variável de concelho para concelho (fig. 6) (F. Félix, 2014).

Desta forma, tornam-se bem visíveis as limitações que um espaço de montanha coloca ao combate aos incêndios florestais, especialmente ao seu ataque inicial. Como o relevo destes espaços coloca entraves à operacionalidade do combate, ao limitar as deslocações dos meios terrestres, torna-se necessário implementar medidas específicas, ajustadas a estas especificidades, que permitam ultrapassar estas limitações e promover a eficácia da primeira intervenção.

\section{Resultados e discussão}

Os anos com maior área ardida foram, por ordem de importância, os de 2012, 2001 e 2013 e foram aqueles que também registaram um maior número de ocorrências, o que nem sempre é uma regra, pois, por exemplo, o ano de 2010 teve 18 ocorrências, portanto mais do que os anos de 2005, 2006 e 2009, mas registou uma área ardida menor que esses mesmos anos (TABeLA VII e fig. 7). Com efeito, apesar de condições meteorológicas favoráveis potenciarem o aumento do número de ignições, nem sempre a existência de muitas ignições se traduz em elevadas áreas ardidas. De facto, a localização do ponto de ignição, em associação com o tipo e caraterísticas da vegetação e do relevo, em função do declive e da exposição, é que vai influenciar o comportamento inicial do incêndio, pelo que nas áreas montanhosas é maior

TABELA VII - Número anual de ocorrências e de hectares de área queimada por incêndios florestais ( $\geq 1 \mathrm{ha}$ ), no período de 2001 a 2013.

$T_{A B L E}$ VII - Annual number of occurrences and hectares of burnt area by forest fires ( $\geq 1 \mathrm{ha}$ ) in the period 2001-2013.

\begin{tabular}{|r|r|r|}
\hline Ano & Ocorrências & Área Ardida \\
\hline 2001 & 34 & 2281,62 \\
\hline 2002 & 0 & 0,00 \\
\hline 2003 & 0 & 0,00 \\
\hline 2004 & 0 & 0,00 \\
\hline 2005 & 3 & 553,91 \\
\hline 2006 & 10 & 389,86 \\
\hline 2007 & 3 & 17,00 \\
\hline 2008 & 10 & 96,71 \\
\hline 2009 & 24 & 412,19 \\
\hline 2010 & 18 & 250,63 \\
\hline 2011 & 17 & 831,42 \\
\hline 2012 & 38 & 2819,89 \\
\hline 2013 & 23 & 2002,34 \\
\hline Total & 180 & 9655,55 \\
\hline
\end{tabular}

a probabilidade de se registarem vastas áreas ardidas. Por outro lado, um elevado número de ocorrências simultâneas ou a existência de curtos intervalos de tempo entre ocorrências sucessivas, faz diminuir os meios de combate disponíveis, o que pode influenciar negativamente o combate inicial de novas ocorrências, tanto pela fraca disponibilidade de meios (capacidade de concentração) como pela fadiga dos combatentes.

Nos três anos em que as áreas ardidas foram as mais elevadas interessa saber que apesar de terem registado dezenas de ocorrências, apenas algumas destas se transformaram em grandes incêndios florestais ( $\geq 100 \mathrm{ha}$ ), sendo essas as responsáveis pela dimensão das áreas ardidas, ou seja, "uma só ocorrência pode transformar um ano de grande mestria no que concerne ao combate aos incêndios, num ano negro na defesa da floresta contra incêndios florestais" (F. Félix, 2014), pelo que a eficácia da primeira intervenção é sempre de extrema importância, nunca podendo ser descurada.

Assim, quando analisamos as classes relativas ao tempo que foi medido entre o alerta e o início do ataque, verificamos que a classe com mais ocorrências é a de 6 a10 minutos, com 80 ocorrências, e que se traduziu em 3 955, 58 hectares de área ardida, ou seja, cerca de $44 \%$ do total da área queimada. Por sua vez, a classe com menos ocorrências é a dos tempos de ATI>20 min., com 14 ocorrências, mas que foi responsável por cerca de $23 \%$ da área ardida, ou seja 2 260,61 hectares, sendo a classe em que, em média, ardeu mais área, ou seja, por cada ocorrência em que o tempo de ataque inicial foi >20 min., a área ardida foi, em média, de 161,47 ha., quase o triplo da classe mais próxima (TABELA VIII). Por outro lado, à medida que aumentou o tempo do início da intervenção, cresceu também, com a exceção da classe de 16-20 min., o valor médio das respetivas áreas ardidas (fig. 8).

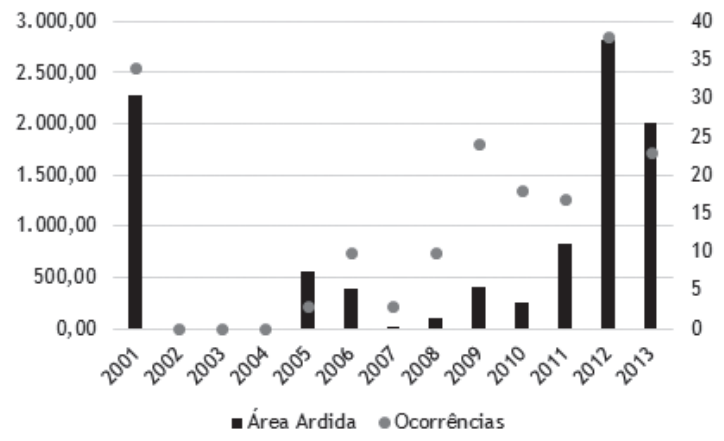

Fig. 7 - Evolução anual das ocorrências e das áreas ardidas em incêndios florestais ( $\geq 1$ ha), nos concelhos da serra da Lousã, entre 2001 e 2013 (após os filtros realizados).

Fig. 7 - Annual evolution of occurrences and burnt areas of forest fires ( $\geq 1 \mathrm{ha}$ ) in the municipalities of Lousã Mountain, between 2001 and 2013 (after the filters performed). 
TABeLA VIII - Ocorrências e área ardida, por classe de tempo de ataque inicial, entre 2001 e 2013.

TABLE VIII - Occurrences and burned area by time classes of the initial attack, between 2001 and 2013.

\begin{tabular}{|c|c|c|c|c|c|}
\hline 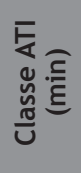 & 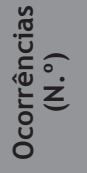 & 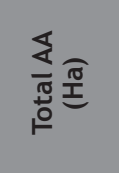 & 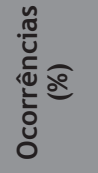 & $\ll ð$ & 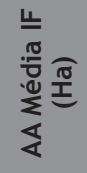 \\
\hline $1-5$ & 23 & 758,81 & 12,78 & 7,86 & 32,99 \\
\hline $6-10$ & 80 & $3.955,58$ & 44,44 & 40,97 & 49,44 \\
\hline $11-15$ & 48 & $2.636,74$ & 26,67 & 27,31 & 54,93 \\
\hline $16-20$ & 15 & 43,82 & 8,33 & 0,45 & 2,92 \\
\hline$>20$ & 14 & $2.260,61$ & 7,78 & 23,41 & 161,47 \\
\hline Total & 180 & $9.655,55$ & 100,00 & 100,00 & 53,64 \\
\hline
\end{tabular}

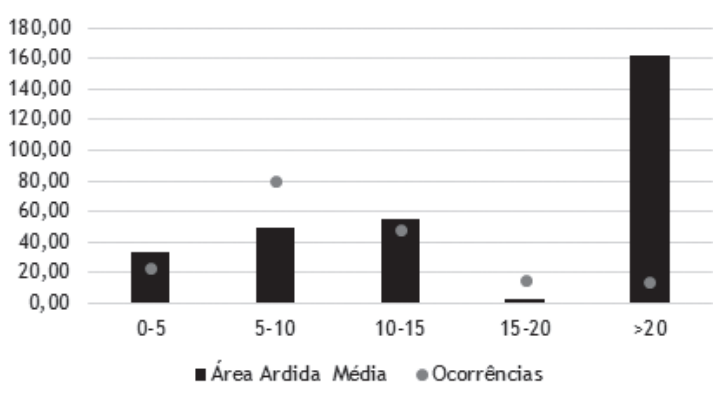

Fig. 8 - Média da área ardida por classe de tempo de ataque inicial e número de ocorrências, entre 2001 e 2013.

Fig. 8 - Averaged burnt area by time classes of the initial attack and number of occurrences, between 2001 and 2013.

De facto, foram os grandes incêndios florestais, com apenas com 19 ocorrências, ou seja, 10,56\% das ignições, os responsáveis por $86 \%$ da área ardida no período em análise (TABELA IX).
De modo a assegurar a prontidão de resposta no combate a incêndios florestais, todos os anos o Estado constituiu e assegura um Dispositivo Especial de Combate a Incêndios Florestais (DECIF) que garante, em permanência, uma resposta operacional adequada e articulada, em conformidade com os graus de gravidade e probabilidade de incêndios florestais durante os períodos considerados de maior risco, através da contratualização de Equipas de Combate a Incêndios Florestais (ECIN) para assegurarem a primeira intervenção (ANPC. 2012).

O Decreto de Lei 156/2004, de 30 de Junho, definiu que o período de maior probabilidade de ocorrência de incêndios florestais se centra entre os dias 1 de julho e 30 de setembro e define um total de cinco fases de risco.

Apesar da organização do DECIF pretender ser flexível e diferenciada, face à probabilidade ou histórico das ocorrências, previsibilidade de intensidade e suas consequências, bem como do grau necessário de prontidão e mobilização das estruturas, forças e unidades de proteção e socorro, na prática é rigoroso e estático no que concerne ao ataque inicial. A título de exemplo, nos períodos previsíveis de menor risco de incêndio, onde o dispositivo é reduzido e a prontidão é também mais reduzida, há cada vez mais situações especiais, provenientes de condições meteorológicas adversas, fora de época crítica, que face ao reduzido número de bombeiros e meios contratados, por vezes acabam por se traduzir em grandes áreas ardidas (F. Félix, 2014).

Ora, analisando as ocorrências e as áreas ardidas, verifica-se que nas classes dos 1-5 e 6-10 minutos as ocorrências e as áreas ardidas têm maior representatividade dentro deste período crítico.

TABELA IX - Ocorrências e área ardida por classe de tempo de ataque inicial e por tipologia (incêndio -1 a 99 ha - ou grande incêndio $-\geq 100$ ha), no período compreendido entre 2001 e 2013.

$T_{A B L E} I X$ - Occurrences and burnt area by time classes of the initial attack and by type (fire - 1 to 99 ha- or large fire - $\geq 100 \mathrm{ha}$ ) in the period between 2001 and 2013.

\begin{tabular}{|c|c|c|c|c|c|c|c|}
\hline \multirow{2}{*}{$\begin{array}{l}\text { Classe ATI } \\
\text { (min.) }\end{array}$} & \multirow{2}{*}{$\begin{array}{c}\text { Ocorrências } \\
\left(\mathrm{N} .^{\circ}\right)\end{array}$} & \multirow{2}{*}{$\begin{array}{l}\mathrm{AA} \\
(\mathrm{Ha})\end{array}$} & \multicolumn{5}{|c|}{ Ocorrências por tipologia } \\
\hline & & & $\mathrm{Ha}$ & n. ${ }^{\circ}$ & $\mathrm{AA}$ & \% Ocorr. & $\%$ AA \\
\hline \multirow{2}{*}{$1-5$} & \multirow{2}{*}{23} & \multirow{2}{*}{758,81} & $1-99$ & 21 & 292,67 & 11,67 & 3,03 \\
\hline & & & $\geq 100$ & 2 & 466,14 & 1,11 & 4,83 \\
\hline \multirow{2}{*}{$6-10$} & \multirow{2}{*}{80} & \multirow{2}{*}{3955,58} & $1-99$ & 71 & 517,10 & 39,44 & 5,36 \\
\hline & & & $\geq 100$ & 9 & 3438,48 & 5,00 & 35,61 \\
\hline \multirow{2}{*}{$11-15$} & \multirow{2}{*}{48} & \multirow{2}{*}{2636,74} & $1-99$ & 42 & 456,02 & 23,33 & 4,72 \\
\hline & & & $\geq 100$ & 6 & 2180,72 & 3,34 & 22,59 \\
\hline \multirow{2}{*}{$16-20$} & \multirow{2}{*}{15} & \multirow{2}{*}{43,82} & $1-99$ & 15 & 43,82 & 8,33 & 0,45 \\
\hline & & & $\geq 100$ & 0 & 0,00 & 0,00 & 0,00 \\
\hline \multirow{2}{*}{$>20$} & \multirow{2}{*}{14} & \multirow{2}{*}{2260,61} & $1-99$ & 12 & 41,60 & 6,67 & 0,43 \\
\hline & & & $\geq 100$ & 2 & 2219,01 & 1,11 & 22,98 \\
\hline \multirow[b]{2}{*}{ Total } & \multirow{2}{*}{180} & \multirow{2}{*}{9655,56} & $1-99$ & 161 & 1351,20 & 89,44 & 13,99 \\
\hline & & & $\geq 100$ & 19 & 8304,35 & 10,56 & 86,01 \\
\hline
\end{tabular}


Contudo, na classe dos 11-15 minutos, as ocorrências de incêndios florestais fora do período crítico, embora em muito menor número do que as registadas no período crítico, pouco mais de metade, no entanto foram responsáveis por uma maior percentagem de áreas ardidas do que as registadas dentro do período crítico.

Nas duas últimas classes, 16-20 e >20 min., os incêndios florestais foram em maior número fora do período critico, muito provavelmente por falta do DECIF e da prontidão dos meios. Embora no primeiro caso (1520 min.) não se tenham traduzido em áreas ardidas significativas, na segunda situação, referente à classe $>20$ min., eles ocorreram sobretudo fora do período crítico e foram responsáveis por $23,33 \%$ do total das áreas ardidas (TABELA X), o que não pode deixar de ser considerado significativo.

Com o estabelecimento de um período crítico, entre 1 de julho e 30 de setembro, pretende-se uma maior adequação dos meios de combate aos habituais graus de risco mais elevados durante a época estival, visando alcançar-se um melhor planeamento e distribuição dos meios ao longo de todo o ano, assegurando apenas durante esse período crítico a permanência e prontidão de um dispositivo especial de combate a incêndios florestais, pelo que fora desse período crítico o combate é assegurado pela atividade normal dos corpos de bombeiros. No caso em estudo, apesar das condições atmosféricas serem mais adversas no período crítico, ardeu mais fora período crítico, o que é explicado, em grande parte, pelo facto do tempo de reposta se encontrar mais debilitado.

Um outro aspeto relevante a ter em conta é que cerca de $44 \%$ do total da área ardida ocorreu dentro do período crítico, quando o Dispositivo Especial de Defesa da Floresta
Contra Incêndios Florestais está no seu auge. Contudo, como a estratégia de combate assenta no estacionamento dos meios nos quartéis, o que associado à sinuosidade do sistema rodoviário, atrasa o tempo de resposta da primeira intervenção, que se quer rápida, vai contribuir para o aumento das áreas ardidas (F. Félix, 2014).

Por outro lado, cerca de $56 \%$ da área ardida é registada fora do período crítico, ou seja, se às mesmas condicionantes físicas, lhe juntarmos um menor grau prontidão de meios humanos e mecânicos, assim como o sistema de deteção e vigilância se encontra reduzido, o sistema de combate tem mais dificuldade em dar resposta, aumentando o tempo da primeira intervenção, o que, em regra, se traduziu num aumento das áreas ardidas (fig. 9), apesar do número de ocorrências ser menor fora do período crítico $(37,78 \%)$ arde mais $(56,15 \%)$ (TABELA XI).

Com efeito, a classe $>20$ min. é responsável por $23,41 \%$ do total da área ardida, dos quais $23,33 \%$ ocorreram fora do período crítico, quando não existiu DECIF, não estando assegurada a prontidão dos meios, o que se traduziu na destruição de milhares de hectares de floresta.

De facto, os grandes incêndios florestais (>100 hectares) dizem respeito apenas a 19 ocorrências, mas foram responsáveis por uma área ardida de 8 304,35 hectares, o que representa $86 \%$ do total da área ardida (TABELA IX).

Se, agora, analisarmos as ocorrências que deram origem aos 19 grandes incêndios florestais e confrontarmos com o tempo da primeira intervenção (TABELA IX) verificamos que a classe de 11-15 min. que corresponde a 6 ocorrências $(31,58 \%)$ representam $26,26 \%$ das área ardidas. Por seu lado a classe $\geq 20 \mathrm{~min}$. com apenas 2 ocorrências (10,53\%) é responsável por $26,72 \%$ das áreas ardias, ou seja juntas são responsáveis por $52,98 \%$ das áreas ardidas.

TABELA X - Ocorrências e área ardidas por classe de tempo de ataque inicial, dentro e fora do período crítico, entre 2001 e 2013.

$T_{A B L E} X$ - Occurrences and burnt areas by time classes of the initial attack, inside and outside of the critical period, between 2001 and 2013.

\begin{tabular}{|c|c|c|c|c|c|c|c|}
\hline $\begin{array}{c}\text { Classe } \\
\text { ATI }\end{array}$ & Tipo & $\begin{array}{c}\text { Dentro Período } \\
\text { Crítico (DPC) }\end{array}$ & $\begin{array}{c}\text { Fora Período } \\
\text { Crítico (FPC) }\end{array}$ & Total & $\begin{array}{c}\text { DPC } \\
(\%)\end{array}$ & $\begin{array}{c}\text { FPC } \\
(\%)\end{array}$ & $\begin{array}{c}\text { Total } \\
(\%)\end{array}$ \\
\hline \multirow{2}{*}{$1-5$} & $\mathbf{N} \cdot{ }^{\circ}$ de Ocorrências & 18 & 5 & 23 & 10,00 & 2,78 & 12,78 \\
\cline { 2 - 8 } & Área Ardida & 499,57 & 259,24 & 758,81 & 5,18 & 2,69 & 7,87 \\
\hline \multirow{2}{*}{$6-10$} & N. ${ }^{\circ}$ de Ocorrências & 55 & 25 & 79 & 30,56 & 13,89 & 44,45 \\
\cline { 2 - 8 } & Área Ardida (Ha) & 2720,18 & 1235,40 & 3955,58 & 28,17 & 12,79 & 40,96 \\
\hline \multirow{2}{*}{$\mathbf{1 1 - 1 5}$} & N. ${ }^{\circ}$ de Ocorrências & 31 & 17 & 48 & 17,22 & 9,44 & 26,66 \\
\cline { 2 - 8 } & Área Ardida (Ha) & 982,97 & 1653,77 & 2636,74 & 10,18 & 17,13 & 27,31 \\
\hline \multirow{2}{*}{$\mathbf{1 6 - 2 0}$} & N. ${ }^{\circ}$ de Ocorrências & 6 & 9 & 15 & 3,33 & 5,00 & 8,33 \\
\cline { 2 - 8 } & Área Ardida (Ha) & 23,4 & 20,42 & 43,82 & 0,24 & 0,21 & 0,45 \\
\hline \multirow{2}{*}{$>20$} & N. ${ }^{\circ}$ de Ocorrências & 2 & 12 & 14 & 1,11 & 6,67 & 7,78 \\
\cline { 2 - 8 } & Área Ardida (Ha) & 8,00 & 2252,61 & 2260,61 & 0,08 & 23,33 & 23,41 \\
\hline \multirow{2}{*}{ Total } & N. ${ }^{\circ}$ de Ocorrências & 112 & 68 & 180 & 62,22 & 37,78 & 100,00 \\
\cline { 2 - 8 } & Área Ardida (Ha) & 4234,11 & 5421,44 & 9655,55 & 43,85 & 56,15 & 100,00 \\
\hline
\end{tabular}




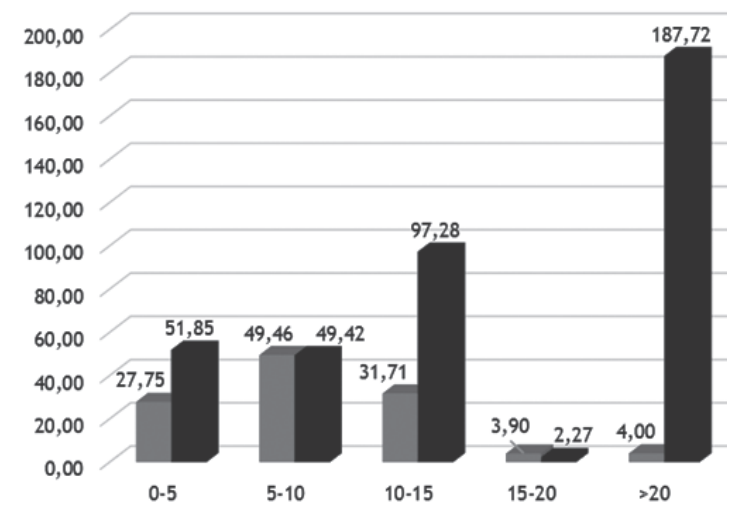

- Dentro do Período Critico a Fora do Período Critico

Fig. 9 - Área média ardida por incêndio dentro e fora do perdido critico, por classe de tempo de ataque inicial, entre 2001 e 2013.

Fig. 9 - Average burnt area by fire and inside and outside of the critical period, by time classes of the initial attack, between 2001 and 2013.
Contudo, mesmo com tempos de resposta baixos ( $\leq$ 10 minutos), as 11 ocorrências $(57,9 \%)$ representaram 47,02\% das áreas ardidas (3 904,62 ha), o que significa que, mesmo com uma intervenção rápida, se registaram grandes áreas ardidas. Então, se a intervenção foi atempada, como justificar as áreas ardidas?

São vários os fatores que ajudam a explicar a dimensão das áreas ardidas, dado que estão dependentes não só das condições meteorológicas mas também de outras condicionantes geográficas em que ocorre.

Nesse sentido é fundamental que se analisem as características intrínsecas dos espaços florestais, designadamente sua suscetibilidade, onde a orografia, em particular através dos declives, facilita a progressão por imprimir maior velocidade à propagação, mas também porque dificulta o uso dos meios terrestres de combate, ligeiros ou pesados. De facto, os terrenos acidentados dificultam a deslocação em segurança

TABELA XI - Grandes incêndios florestais por tempo de resposta e período (crítico/não crítico) em que ocorreram.

$T_{A B L E} X I$ - Large forest fires by response time and by (critical / not critical) period in which they occurred.

\begin{tabular}{|c|c|c|c|c|c|}
\hline 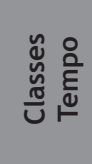 & 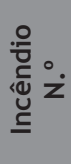 & 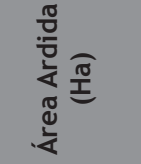 & $\begin{array}{l}* \\
\frac{0}{0} \\
\frac{0}{0} \\
\frac{1}{\alpha}\end{array}$ & 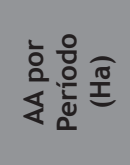 & 这음웡 \\
\hline \multirow{2}{*}{$1-5$} & 1 & 243,500 & DPC & 243,50 & 52,24 \\
\hline & 2 & 222,635 & FPC & 222,64 & 47,76 \\
\hline \multirow{9}{*}{$6-10$} & 3 & 225,000 & DPC & \multirow{7}{*}{2359,93} & \multirow{7}{*}{68,63} \\
\hline & 4 & 207,930 & DPC & & \\
\hline & 5 & 120,000 & DPC & & \\
\hline & 6 & 103,000 & DPC & & \\
\hline & 7 & 354,000 & DPC & & \\
\hline & 8 & 110,000 & DPC & & \\
\hline & 9 & 1240,000 & DPC & & \\
\hline & 10 & 168,750 & $\mathrm{FPC}$ & \multirow{2}{*}{1078,55} & \multirow{2}{*}{31,37} \\
\hline & 11 & 909,800 & FPC & & \\
\hline \multirow{6}{*}{$11-15$} & 12 & 107,000 & DPC & \multirow{4}{*}{707,30} & \multirow{4}{*}{32,43} \\
\hline & 13 & 222,000 & DPC & & \\
\hline & 14 & 205,800 & DPC & & \\
\hline & 15 & 172,500 & DPC & & \\
\hline & 16 & 501,420 & $\mathrm{FPC}$ & \multirow{2}{*}{1473,42} & \multirow{2}{*}{67,57} \\
\hline & 17 & 972,000 & FPC & & \\
\hline $16-20$ & --- & $--\cdot$ & -- & -- & --- \\
\hline \multirow{2}{*}{$>20$} & 18 & 476,710 & DPC & 476,71 & 21,48 \\
\hline & 19 & 1742,300 & FPC & 1742,30 & 78,52 \\
\hline \multirow{2}{*}{ Total } & \multirow{2}{*}{19} & \multirow{2}{*}{8304,350} & DPC & 3787,44 & 45,61 \\
\hline & & & FPC & 4516,91 & 54,39 \\
\hline
\end{tabular}

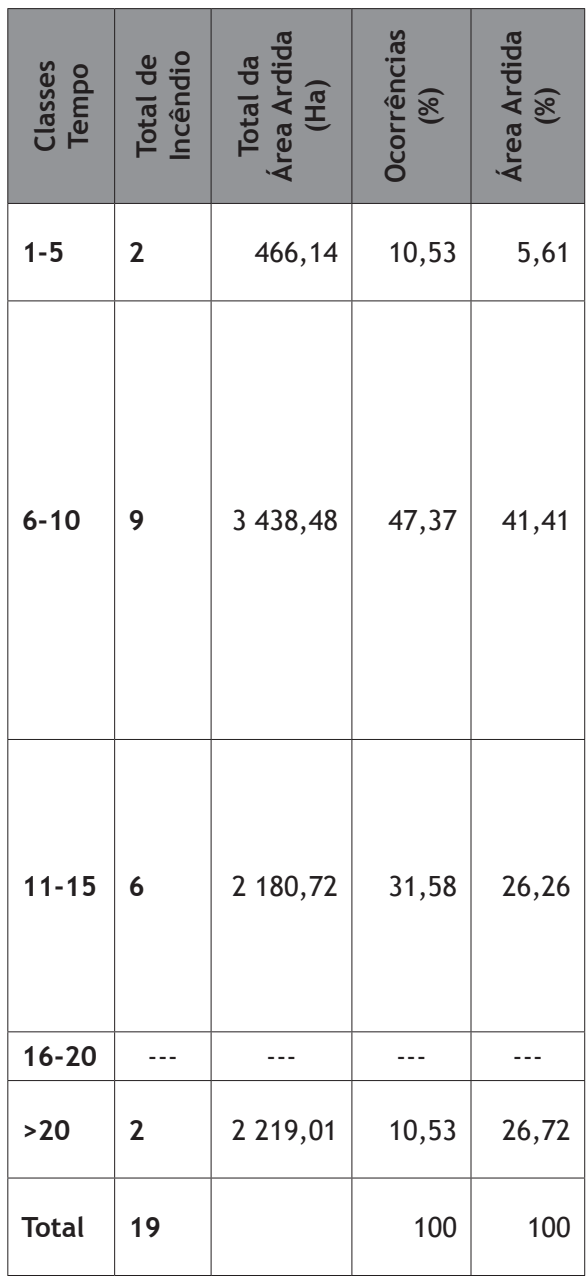

* DPC - Dentro do Período Critico; FPC - Fora do Período Critico. 
e o acesso aos locais onde os incêndios começam, reduzindo a eficácia da primeira intervenção (que se quer rápida), contribuindo para que um foco de incêndio nascente possa evoluir rapidamente, progredindo por vertentes declivosas e vales encaixados, aumentado consideravelmente a área ardida e onde o combate passa a ser mais difícil, podendo mesmo causar feridos e, até, mortes (F. Félix, 2014).

Deste modo, torna-se necessário localizar as áreas mais sensíveis, onde o ataque inicial deve ser mais atempado, colocando os tempos de reposta em consonância com o grau de comportamento do fogo, pois as áreas com bastante biomassa disponível, elevadas taxas de combustibilidade e fortes declives, aumentam a capacidade de propagação, pelo que as chamas irão ter uma rápida evolução, ao ponto de que quando chegam os meios de ataque inicial, frequentemente eles já não conseguem dominar a situação e a sua evolução origina grandes áreas ardias.

Nesse sentido usámos os mapas de declives, de uso do solo e de recorrência que foram reclassificados e somados diretamente (fig. 10), para darem origem a um mapa de suscetibilidades, a partir do qual se pretendem identificar as áreas criticas (fig. 11) (E. Chuvieco et al, 1997).

Verificamos, então, que a maior parte do território na nossa área de estudo se encontra em áreas de suscetibilidade elevada ou superior (fig. 12), fortemente relacionadas com a serra, quer em termos de uso do solo, quer dos declives.

A classe de suscetibilidade mais representativa é a elevada, cerca de $60 \%$, que com a classe muito elevada e máxima representam cerca de $68 \%$ da área de estudo (TABELA XII).

As áreas de suscetibilidades elevada e superiores necessitam de una análise cuidada, não só localizando-as mas verificando qual será o tempo de resposta se houver uma ignição.

Para a realçar a importância do jogo entre a distância e a velocidades, ou seja, os tempos de deslocação, e como $60 \%$ da área de estudo é da classe de suscetibilidade elevada, optou-se por filtrar apenas as classes de suscetibilidade muito elevada e máxima (7,79\% e 0,09\%), que se concentram no bloco central e se estendem para nordeste e sudoeste, com algumas áreas isoladas a norte de Serpins e de Miranda do Corvo (fig. 12).

Pretendeu-se confrontar as áreas de suscetibilidade muito elevada e máxima com os tempos de deslocação, com destaque para os tempos superiores a 15 minutos, de modo a validar se a intervenção atempada estará assegurada ou onde se verifica a ausência de acessos e, ainda, se adicionou a variável demográfica da população residente nos principais lugares cujos tempos de deslocação são superiores a 15 minutos e se encontram sobrepostos ou na proximidade de áreas criticas.

A fig. 12 mostra-nos claramente que em algumas destas áreas críticas verificamos a ausência de acessos pelo que, nestes casos, no acionamento dos meios deve ser dada prioridade à ativação dos meios aéreos, passando os meios terrestres para as áreas circundantes, controlando a evolução do incêndio, ajudando nas instruções ao meio aéreo e averiguando potenciais projeções, que podarão originar focos de incêndio secundários.

A análise à distribuição da população mostrou que o principal problema já não se encontra no bloco central da serra, mas sim nas suas bordaduras, embora no concelho de Góis esta população se situe no meio dos dois corpos de bombeiros, enquanto que no caso do concelho da Lousã a população se encontra distribuída ao longo das duas estradas que atravessam a serra.

A sudoeste existem também algumas situações, na transição do concelho de Miranda do Corvo para o de Penela, com este a apresentar, a sul, grandes lacunas devido à grande distância entre estas áreas e as corporações de bombeiros mais próximas.

A missão dos bombeiros é salvar pessoas e bens. A solução passará irremediavelmente pela dispersão estratégica dos meios pelo território como media de prevenção pro-ativa.

Para compreender melhor cada um dos 19 grandes incêndios florestais, seria vantajoso localizar os respetivos pontos de ignição. Contudo, usando a cartografia em formato shapefile disponibilizada pelo ICNF não se conseguiu localizar com precisão as 19 ocorrências por as coordenadas existentes serem relativas à sede de freguesia ou à igreja matriz. Por outro lado, seria necessária ter também a informação do uso do solo à escala local, mas como o Corine Land Cover é à escala 1/100 000, não serve para este objetivo, e, como a COS - Carta de Ocupação do Solo, à escala 1/25 000 não se encontra disponível gratuitamente, não foi possível realizar com êxito essa localização.

Um outro facto que também pode contribuir para ajudar a explicar a dimensão das áreas ardidas, está relacionado com as características técnicas das equipas intervenientes, ou seja, que formação e experiência possuíam e quais os veículos utilizados. Como essa informação também não consta nas tabelas disponíveis no ICNF, não pôde ser tida em consideração. Por exemplo, seria útil saber as condições em que decorreu uma primeira intervenção que chegou à ignição em menos de 5 minutos, designadamente se foi efetuada por um único $\mathrm{VLCl}$, com capacidade de $500 \mathrm{~L}$, numa área com muitos combustíveis, de grande combustibilidade e com fortes declives. De facto, como interessa chegar ao ponto de ignição no menor tempo possível e com 
a disponibilidade de água suficiente para proceder à extinção do foco de incêndio, é necessário planear e ajustar os tempos de deslocação e os meios terrestres de combate disponíveis ao risco de incêndio. Depois, a mesma capacidade de água pode ser usada de forma diferente consoante a experiência e a formação do

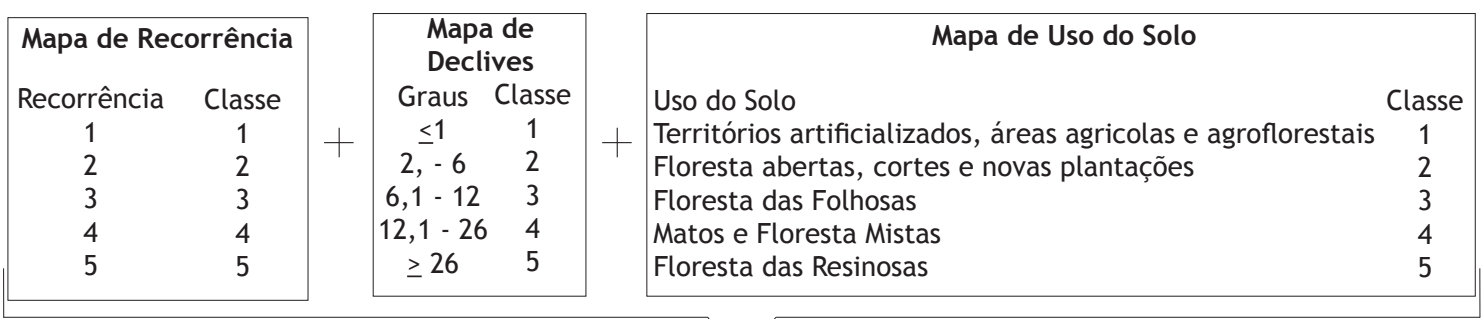

\section{Mapa de Suscetibilidades}

Fig. 10 - Organigrama metodológico do mapa de suscetibilidades (F. Félix, 2014).

Fig. 10 - Methodological organization for the susceptibilities map calculation (F. Félix, 2014).

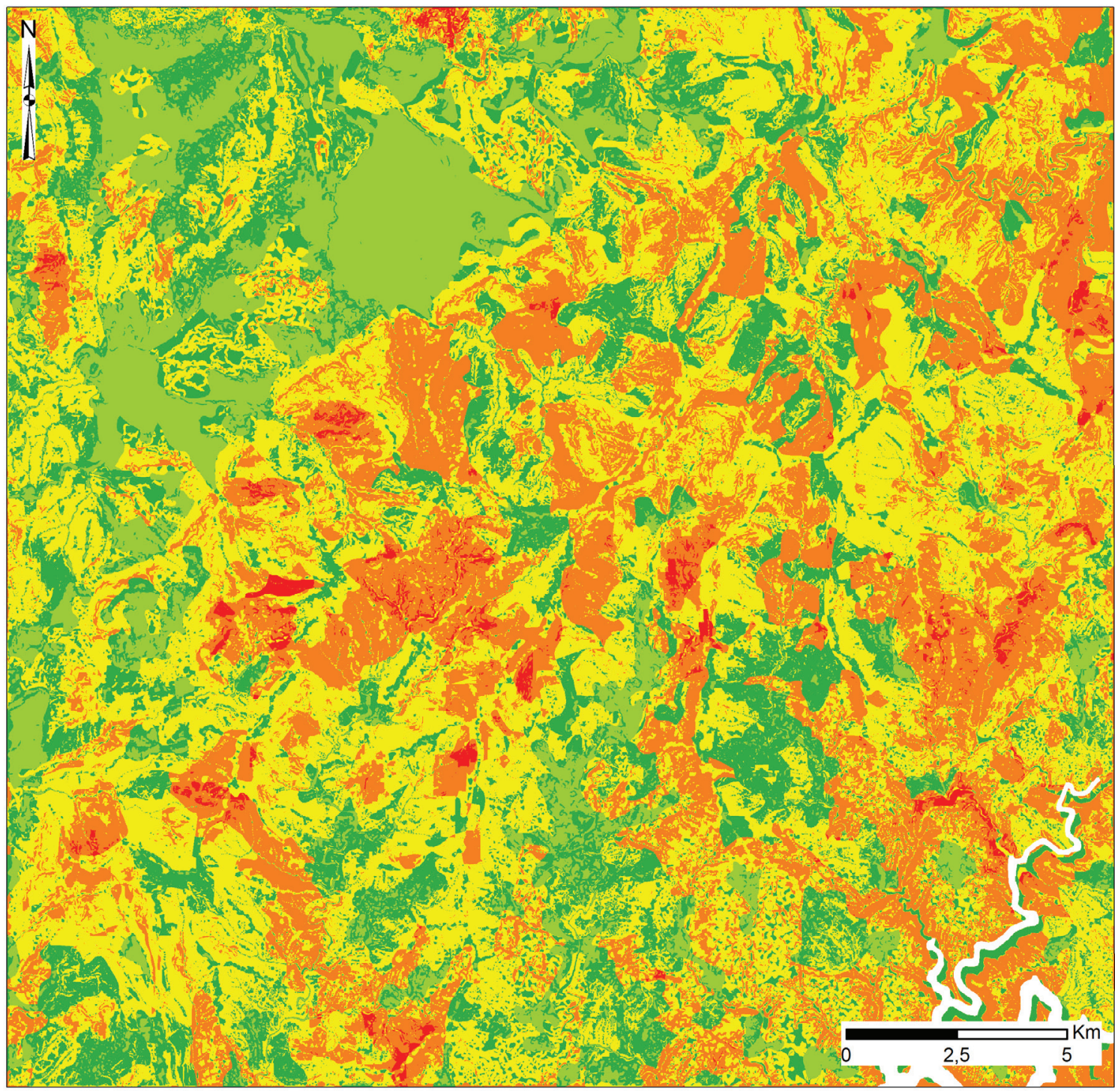

Suscetibilidade:

Reduzida

Moderada

Elevada

Muito Elevada

Máxima

Fig. 11 - Mapa de suscetibilidade de incêndio florestal na serra da Lousã (F. Félix, 2014).

Fig. 11 - Forest fire susceptibility map in the Lousã.Mountain (F. Félix, 2014). 
TABELA XII - Classificação da Área de estudo, quanto à suscetibilidade a incêndios florestais-

TABLE XII - Classification of the study area, as to susceptibility to forest fires.

\begin{tabular}{|c|c|c|c|c|}
\hline Suscetibilidades & Hectares & $\mathrm{Km}^{2}$ & \multicolumn{2}{|c|}{$\%$} \\
\hline Reduzida & 70786071,61 & $70.786,07$ & 11,64 & \multirow{2}{*}{31,92} \\
\hline Moderada & 123322796,20 & $123.322,80$ & 20,28 & \\
\hline Elevada & 366430549,20 & $366.430,55$ & 60,26 & \multirow{3}{*}{68,08} \\
\hline Muito Elevada & 46972325,67 & $46.972,33$ & 7,72 & \\
\hline Máxima & 556820,06 & 556,82 & 0,09 & \\
\hline Total sem rede hidrográfica & $608.068 .562,75$ & $608.068,56$ & 100,00 & 100,00 \\
\hline
\end{tabular}

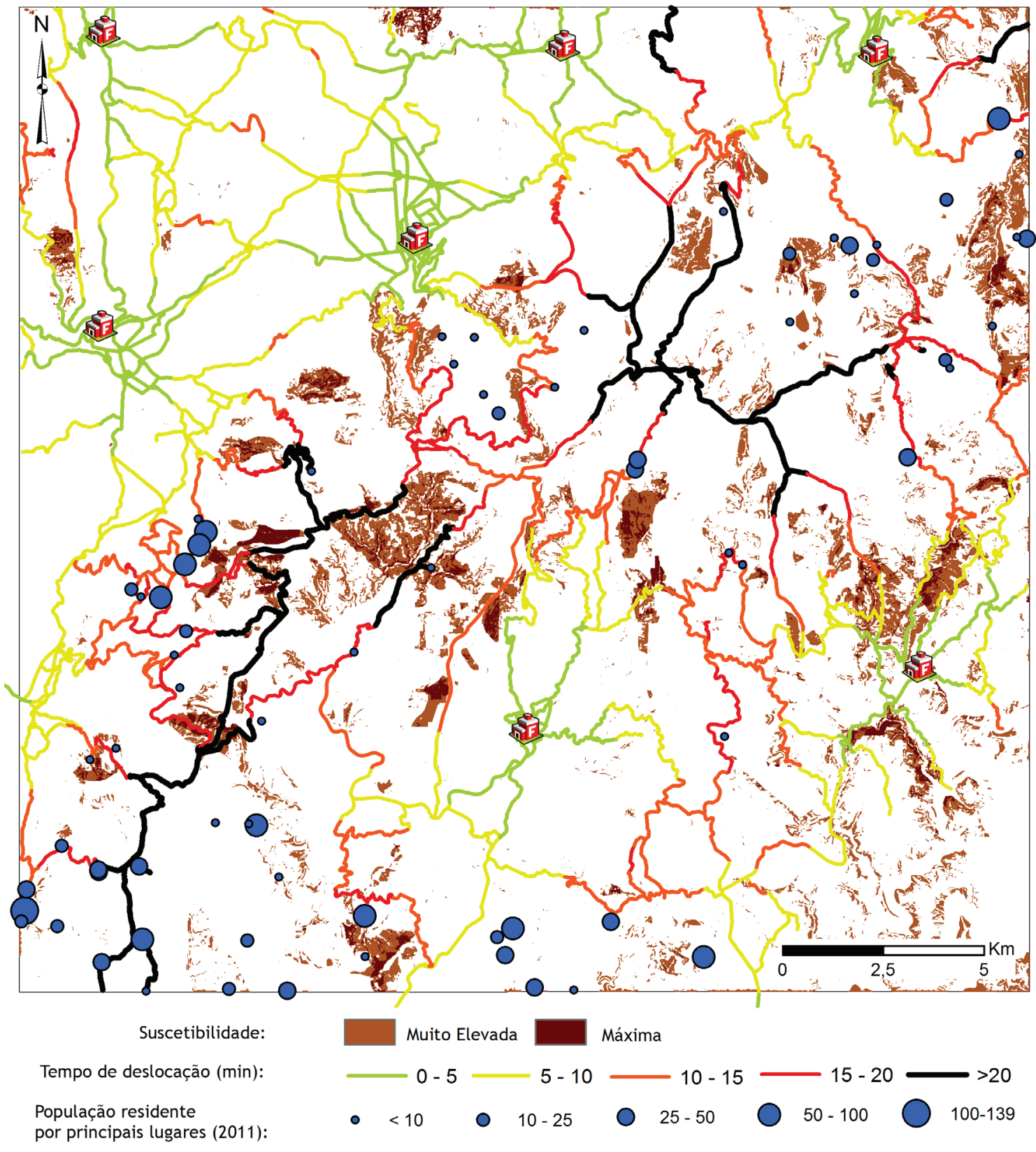

Fig. 12 - Localização das áreas de suscetibilidade muito elevada e máxima a incêndios florestais e confrontação com o tempo de deslocação dos meios terrestres de combate e principais lugares situados a mais de 15 minutos de deslocação (F. Félix, 2014).

Fig. 12 - Location of very high and maximum forest fires susceptibility areas and confrontation with the travel time of terrestrial combat means of and main places located more than 15 minutes away (F. Félix, 2014). 
bombeiro. Com efeito, mesmo que chegue em tempo oportuno, se fizer um mau uso dos meios disponíveis, debitando muito rapidamente a água disponível, por mau uso da agulheta, pode ficar sem agente extintor e o incêndio continuará a progredir...

Como vimos são vários os aspetos que influenciam a operacionalidade de uma intervenção. Algumas deles de difícil ponderação e outros de acesso muito restrito. Contudo, os declives não poderão ser escamoteados e não podem deixar de ser analisados, sendo um fator decisivo para o sucesso do combate. Nesse sentido os declives assumem-se como um fator chave, pois influenciam a velocidade de deslocação não só das chamas mas também dos meios de combate (TABELA II). A orografia limita o uso dos meios mecânicos de combate, ligeiros e pesados, na medida em que os terrenos acidentados dificultam a deslocação, em segurança, reduzindo a eficiência de uma primeira intervenção que se quer rápida.

\section{Conclusão}

A maior ou menor incidência anual dos incêndios florestais em Portugal, bem como a dimensão das áreas ardidas têm estado muito relacionadas com as condições atmosféricas, apesar de todo o dispositivo de combate contratado para esse efeito, atendendo a que algumas estratégias operacionais não permitiram explorar todo o potencial dos meios e recursos envolvidos.

Todavia, as condições atmosféricas, apesar de terem um grande peso e relevância no comportamento dos incêndios, por si só não explicam nem justificam as áreas ardidas nas últimas décadas. Com efeito, na primeira metade do século $\mathrm{XX}$, atingiu-se a máxima taxa de ocupação agrícola do território. Nessa altura havia muito menos corpos de bombeiros e meios de combate, e, sobretudo, não sendo comparáveis aos modernos. Contudo, como havia muita gente nos campos, o grande número de ignições não resultava em grandes áreas queimadas, pois, a maior parte dos incêndios eram extintos na origem e sem a intervenção dos bombeiros. (J. S. Pereira, 2013).

Então o que é que se alterou? Foram vários os aspetos da sociedade que se foram modificando, na sequência do despovoamento do mundo rural e do abandono dos campos, com a consequente falta de intervenção nos espaços florestais, mas a retirada dos meios de combate então existentes nos campos e na floresta, com a sua posterior colocação nos quartéis de bombeiros, também contribuiu para as consequências registadas.

Como vimos a disponibilidade de meios e a sua localização no quartel dos bombeiros faz com que as suas esferas de atuação não aumentem, sobretudo nas áreas montanhosas, onde um sistema rodoviário sinuoso, que faz aumentar a distância e o tempo de deslocação, faz com que se perca alguma eficácia a nível da primeira intervenção.
Deste modo, sempre que as condições atmosféricas sejam muito favoráveis à ocorrência dos incêndios florestais é desejável que, nas áreas florestais de maior sensibilidade, se proceda à antecipação de meios de combate para locais estratégicos de pré-posicionamento, para que os tempos de reposta da primeira intervenção possam ser mais curtos.

Ora, estando a dimensão da área ardida resultante de uma ignição, associada não só às condições meteorológicas, mas também a outras condicionantes geográficas (J. Pereira et al., 2003), de entre as quais destacamos os declives, porque influenciam a capacidade de propagação das chamas e limitam o uso dos meios terrestres de combate, afetando a sua velocidade de deslocação, aumentando o tempo de reposta, este é um aspeto que não pode deixar de ser analisado, de modo a que se possa tirar o maior proveito das potencialidades dos recursos humanos e mecânicos disponíveis, e assim, diminuir as áreas ardidas.

Para socorrer, primeiro é preciso lá chegar e, diz a sabedoria popular, "que a pressa é inimiga da perfeição".

\section{Referências Bibliográficas}

Abhineet, J., Shirish, A. R., Singh, R. K., Das, K. K., Roy, P. S. (1996). Forest Fire Risk Modelling Using Sensing and Geographic Information System. Current Science. Indian Academy of Science. 70: pp. 928-933.

Alegria, Maria Fernanda (1976). A bacia topográfica da Lousã: características físicas e utilização do solo. In Finisterra, Lisboa, vol. 21 (2), pp. 187-212.

Almeida, Rui (2006). Distribuição dos meios de combate a incêndios face à distribuição das manchas florestais. Disponível em: http://www.researchgate. net/publication/271587087.

Amaro, Antonio Duarte (2009). O socorro em Portugal. Organização, formação e cultura de segurança nos corpos de bombeiros, no quadro da Protecção Civil (Tese de Doutoramento). Faculdade de Letras, Univ.do Porto.

ANPC - AUTORIDADE NACIONAL DE PROTEÇ̃̃O CIVIL (2012). Diretiva Operacional Nacional (DON) n. ${ }^{\circ} 2$ - DFCl - Dispositivo Especial de Combate a Incêndios Florestais, Março de 2012.

Aranha, J. (2004). Índice de Aptidão para o Combate a Fogos Florestais. VII Encontro de Utilizadores de Sistemas de Informação Geográfica - ESIG, Oeiras.

Baptista, F. O. e Santos, R. T. (2005). Os Proprietários Florestais. Oeiras, Portugal: Celta Editora.

Bento-Gonçalves, A., Vieira, A., Ferreira-Leite, F., Oliveira Martin S, C., e Costa Silva, F. (2010). A desestruturação do mundo rural em áreas de montanha e o risco de incêndio - o caso da serra da Cabreira (Vieira do Minho). Territorium, 17, 109-117. 
Buck, C. J. (1936). Forest roads or forest fires?. Regional Forester, U. S. Forest Service. Pacific Sportsman, 401 Sansome Street, San Francisco, California.

Butler, B.W.; Anderson, W. R and Cachpoe, E. A (2007) Influence of slope on fire spread rate. USDA Forest Service Proceedings RMRS-46 CD.

Carmo, M., Moreira, F., Casimiro, P., \& Vaz, P. (2011). Land use and topography influences on wildfire occurrence in northern Portugal. Landscape and Urban Planning, 100(1), 169-176.

Carvalho, Paulo (1998). A Estrada da Serra (LousãCastanheira de Pêra). Notas para uma leitura Geográfica. Separara de: Revista Arunce, n. ${ }^{\circ}$ 13/15, 1998-2000.

Carvalho, Paulo (2008). Património Construído e Desenvolvimento em Áreas de Montanha. O exemplo da Serra da Lousã. Lousã. CML, $1^{a}$ Edição, 657 pp.

Castro, C. F., Serra G., Parola, J., Reis, J., Lourenço, L., Correia, S. (2002). Combate a Incêndios Florestais. Manual de Formação Inicial do Bombeiro. Sintra, Gráfica Europam, Ld ${ }^{\mathrm{a}}$. Vol. XIII.

Chuvieco, E., Congalton, R.G. (1989). Application of remote sensing and geographic systems to forest fire hazard mapping. Remote sensing of environment, v.29, p.147-59.

Colaço, C. (2006). Os incêndios florestais: o papel dos técnicos florestais (formação) e o contributo do voluntariado ambiental. Centro de Ecologia Aplicada Baeta Neves - Instituto Superior de Agronomia.

Dalvi, M. Q. and Martin, K. (1976). Estimate of non work trip demand: a disaggregated approach. Transportation, June 1980, Volume 9, Issue 2, pp 145-172.

Dias, Pedro; Rebelo, Fernando (1985). Lousã. A Terra e as Gentes. Lousã. C. M. da Lousã. 95 pp.

DSDF - DIVISÃO DE DEFESA DA FLORESTA CONTRA INCÊNDIOS (2004). Incêndios Florestais - 2004, Relatório Provisório (01 Janeiro a 10 Outubro). Direcção Geral dos Recursos Florestais, Lisboa.

DUDEF - DIRECÇÃO DE UNIDADE DE DEFESA DA FLORESTA (2012). Plano Municipal de Defesa da Floresta contra Incêndios (PMDFCl) - Guia Técnico. Autoridade Florestal Nacional, Lisboa.

ENB - ESCOLA NACIONAL DE BOMBEIROS (2001). Manual Técnico de Condução Fora de Estrada. Cadernos Práticos.

EUROPEAN COMMISSION (2004). Forest Fires in Europe - 2003 Fire Campaign. Official Publication of the European Commission.

Félix, F. (2014). Ensaio metodológico sobre a importância da modelação espacial da sinuosidade rodoviária para apoio à decisão no ataque inicial aos incêndios florestais. O exemplo da serra da Lousã
(Tese de Mestrado). Apresentado ao Departamento de Geografia e Turismo da Faculdade de Letras da Universidade de Coimbra, 21 de novembro.

Ferraz, Sílvio F.B., Vettorazzi, Carlos Alberto (1998). Mapeamento de risco de incêndios florestais por meio de sistema de informações geográficas (SIG). In Scientia Forestalis, 53, pp. 39-48

Ferreira, A. (2010). Sistema de Informação Geográfica e Susceptibilidade a Incêndio Florestal. Análise de Metodologias em Ambiente SIG (Tese de Mestrado). Faculdade de Letras da Universidade do Porto.

Ferreira-Leite, F. Bento-Gonçalves, A. Lourenço, L. (2014). Grandes incêndios florestais na década de 60 do século XX, em Portugal continenta. Revista Territorium, n. 21.

Garcia, C. V., Woodard, P. M., Titus, S.J., Adamowicz, W. L., Lee, B. S. (1998). Dos Modelos para la Prediccion de Incendios Forestales en Whitecourt Forest, Canada. Agricultural Research: Forestn Resources System. Vol. 8 (1).

Geertman, S. C. M. e Van Eck, J. R. R. (1995). GIS and models of accessibility potencial: an application in planning. International Journal of Geographical Information Science. Taylor and Francis. Vol. 9, No. 1, p. 67-80.

Govan, Vidhia (2012). Modelos de Análise de Acessibilidade Rodoviária em SIG - Aplicação ao caso de Moçambique. (Dissertação para obtenção do grau de Mestre em Engenharia na Área de Especialização em Vias de Comunicação e Transportes). Instituto Superior de Engenharia de Lisboa.

Gouveia, Maria Manuel Afonso Lopes (2005). Perigo de incêndio florestal no concelho de Mirandela (Dissertação de Mestrado em Gestão dos Riscos Naturais). Faculdade de Letras da Universidade do Porto.

Gonçalves, P.P., Diogo, P.M. (1994). Geographic Information Systems and cellular automata: a new approach to forest fire simulation. Proceedings of the Fifth European Conference and Exhibition on Geographic Information Systems, EGIS '94. Utrecht: EGIS Foundation, p.702-711.

ICNF - INSTITUTO DE CONSERVAÇÃO DANATUREZAE DAS FLORESTAS (2012). Estratégia Nacional para as Florestas.

JAE - JUNTA AUTÓNOMA DE ESTRAdAS (1994). Norma de Traçado. Junta Autónoma de Estradas, Almada, 1994.

Litman, T. (2008). Evaluating Accessibility for Transportation Planning. Victoria, Canada: Victoria Transport Policy Institute. 49p.

Loureiro, A e Faria, J. (2010). Quanto custam os incêndios florestais? Revista da ANEFA - Associação Nacional de Empresas Florestais e Agrícolas e do Ambiente, n. ${ }^{\circ}$ 9, p. 20-21. 
Lourenço, L. (1988). Tipos de tempo correspondentes aos grandes incêndios florestais ocorridos em 1986 no Centro de Portugal. Finisterra XXIII (46): 251-270.

Lourenço, L. (1991a). Aspectos sócio-económicos dos incêndios florestais em Portugal. Biblos, Vol. LXVII, Coimbra, p. 373-385.

Lourenço, L. (1991b). Uma fórmula expedita para determinar o índice meteorológico de risco de eclosão de fogos florestais em Portugal Continental. Separata de Cadernos Científicos sobre Incêndios Florestais, Coimbra, 2, p. 3-63.

Lourenço, L. (1992). Avaliação de Risco de Incêndio nas Matas e Florestas de Portugal Continental. Finisterra. XXVII. Disponível em: http://www.uc.pt/fluc/ nicif/Publicacoes/Estudos_de_Colaboradores/PDF/ Publicacoes_periodicas/FinisterraXXVII_53_54_1992.

Lourenço, Luciano; Bento-Gonçalves, António; Bento, Manuela (2001). Intervenção Humana e risco de Fogo Florestal. Actas do II Colóquio de Geografia de Coimbra, N. ${ }^{\circ}$ Especial de "Cadernos de Geografia", pp. 91-98. Disponível em: http://www.uc.pt/fluc/ nicif / Publicacoes/Estudos_de_Colaboradores / PDF/Comunicacoes_congressos/IIColoquio_de_ Geohgrafia_de_Coimbra_1999.

Lourenço, Luciano, (2006). Incêndios Florestais: algumas reflexões sobre prevenção e mitos de combate. Revista Territorium $\mathrm{n}^{\circ}$ 13, Coimbra, pp. 59-70. Disponível em: http://www.uc.pt/fluc/nicif/riscos/ Documentacao/Territorium/T13_artg/T13art06.pdf.

Lourenço, L. (2014). Risco, perigo e crise. Trilogia de base na definição de um modelo conceptual-operacional. Realidades e Desafios na Gestão dos Riscos, Diálogos entre Ciência e Utilizadores. Núcleo de Investigação de Cientifica de Incêndios Florestais, Faculdade de Letras da Universidade de Coimbra, p. 61-72.

Matos, Artur Teodoro (1980). Transportes e Comunicações em Portugal, Açores e Madeira (1750-1850). vol. 1, Ponta Delgada, Universidade dos Açores, 1980, p. 478.

Mcarthur, A.G. (1968). Fire Behaviour in Eucalypt Forests. Leaflet No. 107. Ninth Commonwealth Forestry Conference, India.

Moreno, J., Vázquez, A., e Vélez, R. (1998). Recent history of forest fires in Spain, in Moreno J. (Ed.), Large Forest Fires, Backhuys Publishers, p. 159-185.

Muñoz, R. V. (2000). La Definición de Incendio Forestal. La Defensa Contra incêndios Forestales Fundamentos e Experiencias. A. G. Brage. Madrid, McGraw-Hill/ Interamericana de España, S. A. U.: 13-16.

Oliveira, S., Bento-Gonçalves, A., Nunes, Adélia, Vieira, A, Félix, F., Lourenço, L. (2014). Prevenção de incêndios florestais e análise da vulnerabilidade com recurso a dado de satélite. O exemplo do projeto PREFER. Livro de resumos do VIII Colóquio de Geografia de Coimbra “Espaço, Natureza e Sociedade, 27 e 28 de março, Coimbra. Disponível em: http://www.uc.pt/fluc/ nicif/Publicacoes/Estudos_de_Colaboradores/PDF / Publicacoes_periodicas/2014_Cad_Geo33_e.pdf.

Pacheco, Elsa (2004). Alteração das acessibilidades e dinâmicas territoriais na Região Norte: expectativas, intervenções e resultantes (Tese de Doutoramento). Faculdade de Letras da Universidade do Porto, GEDES.

Paiva, Jorge (1988). O Coberto Vegetal da Serra da Lousã in Jornadas de Cultura e Turismo. Câmara Municipal da Lousã, Lousã.

Pereira, J. M. C., Carreiras, J. M. B., VasconceloS, M. J. P. (1998). Exploratory data analysis of the spatial distribution of wildfires in Portugal, 1980-1989. Geograph. Systems 5 (4), 355-390.

Pereira, J. M. C e Santos, M. T. N (2003). Fire risk na bruned áreas mapping in Portugal. Lisboa: Direção Geral das Florestas.

Pereira, Mário G., Trigo, Ricardo M., Camara, Carlos C., Pereira, José M.C., Solange, M. L. (2005). Synoptic patterns associated with large summer forest fires in Portugal. Agricultural and Forest Meteorology, 129 (2005) 11 - 25. Elsevier B.V.

Pereira, J. S. (2013). O Futuro da Floresta em Portugal. Fundação Francisco Manuel dos Santos. Depósito Legal n. ${ }^{\circ} 368917 / 13$.

Pina, Maria Helena Mesquita (1997). A região Duriense Alguns apontamentos sobre a sua rede de transpores (séc. XVII - XIX). III Congresso da Geografia Portuguesa, Porto, Setembro. Edições Colubri e APG.

Rautela, Piyoosh; Pant, Swarn Shikher (2007). New methodology for demarcating high road accident risk-prone stretches in mountain roads. Current Science, Vol. 92, no. 8, 25 April.

Rebelo, F. (1994). Risco e Crise. Grandes Incêndios Florestais, Atas do II Encontro Pedagógico sobre Risco Florestal, p. 19-32, Coimbra.

Rego, F., (2001). Florestas públicas. Direção Geral das Florestas e Comissão Nacional Especializada de Fogos Florestais.

Rego, F. (1992). Land use changes and wildfires. Response of Forest Ecosystems to Environmental Changes. Elsevier Applied Science.

Ribeiro, Patrícia (2002). A Força das Chamas. Revista Protecção Civil, III Série, N. ${ }^{\circ}$ 2. Abril, 2002.

Saglam, B., Bilgili, E., Dincdurmaz, B., Kadiogulari, A. I. e Kücük, Ö. (2008). Spatio-Temporal Analysis of Forest Fire Risk and Danger Using LANDSAT Imagery. Sensors. Vol. 8. pp. 3970-3987. 


\section{territorium 24}

Santos, J. P. (2013). O Futuro da Floresta em Portugal. Fundação Francisco Manuel dos Santos, janeiro. Depósito legal n. ${ }^{\circ} 368917 / 13$.

Souto, Ana (2006). ELOZ de Serra e de Rios e de ELOS que se querem LAÇOS! Apresentação de uma abordagem à Serra da Lousã, na prespectiva de quem a sente e assume como projecto de vida. Revista Turismo \& Desenvolvimento, N.Y 6, 2006, pp 145-150.

Strino, J. G., Alhaddad, B., et al. (2007). Remote Sensing Analysis to Detect Fire Risk Locations. Géo Congrès. Quebec, Canada.

Tedim, F., Oliveira, S., Nunes, A, Ferreira, C. e Lourenço, L. (2013). Diálogo entre a ciência e os utilizadores potencialidades e fragilidades na temática dos riscos. Realidades e Desafios na Gestão dos Riscos, Diálogos entre Ciência e Utilizadores. Núcleo de Investigação de Cientifica de Incêndios Florestais, Faculdade de Letras da Universidade de Coimbra, p. 73-86. Disponível em: http://www.uc.pt/fluc/nicif/ Publicacoes/livros/dialogos/Artg07.pdf.

Vasconcelos, A. (2013). Avaliação da suscetibilidade à ocorrência de incêndios florestais no concelho de Leiria (Tese de Mestrado). Sistemas de Informação Geográfica e Modelação Territorial aplicados ao Ordenamento, IGOT, Universidade de Lisboa.
Vélez, R. (1993). High Intensity Forest Fires in the Mediterranean Basin: Natural and Socioeconomic Causes. Disaster Manage, n. 5, p. 16-20.

Vettorazzi, C. e Ferraz, S. (1998). Mapeamento de Risco de Incêndios Florestais por meio de Sistema de Informação Geográfica (SIG). Scientia Forestalis.

Viegas, Domingos Xavier (1989). Manual sobre Incêndios de Florestas, Secretaria-Geral do Ministério do Planeamento e da Administração do Território, Lisboa.

Viegas, Domingos Xavier; Lourenço, Luciano (1989). Os incêndios florestais na região Centro. Revista Sociedade e Território, N. ${ }^{\circ} .9$.

Viegas, Domingos Xavier (2006). Parametic Study of Eruptive Fire Behaviour Model. International Journal of Wildland Fire, 15(2).

Vieira, P. Almeida (2006). Portugal: 0 vermelho e o negro. A verdade amarga e a dolorosa realidade dos incêndios florestais, Dom Quixote, Lisboa, 496 p. 